\title{
Substituente en isomeriese effekte op die reduksie- en oksidasiepotensiaal van tris( $\beta$-diketonato) mangaan(III) komplekse: DFT en MESP analises
}

\section{Outeurs: \\ Adebayo A Adeniyi, a, Jeanet Conradie ${ }^{b, c}$ \\ Affiliasies: \\ ${ }^{a}$ Departement Industriële \\ Chemie, Federale \\ Universiteit Oye Ekiti, Nigerië \\ ${ }^{\mathrm{b}}$ Departement Chemie, Universiteit Troms $\varnothing, \mathrm{N}-9037$ Troms $\varnothing$, Noorweë 'Departement Chemie, Universiteit van die Vrystaat, Posbus 339, Bloemfontein, 9300, Suid- Afrika}

Korresponderende outeur: Adebayo A Adeniyi E-pos: AdeniyiAA@ufs.ac.za;

Datums:

Ontvang: $\quad 30 / 04 / 19$ Aanvaar: $\quad 20 / 08 / 19$ Gepubliseer: 08/11/19

Hoe om hierdie artikel aan te haal:

Adebayo A Adeniyi,

Jeanet Conradie,

Substituente en isomeriese effekte op die reduksieen oksidasiepotensiaal van tris( $\beta$-diketonato) mangaan(III) komplekse: DFT en MESP analises, Suid-Afrikaanse Tydskrif vir Natuurwetenskap en Tegnologie 38(1) (2019). https://doi.org/10.36303/ SATNT.2019.38.1.728

An English copy of this paper is available online at http://www.satnt.ac.za/ index.php/satnt/article/ view/728

Kopiereg:

(C) 2019. Authors.

Licensee: Die Suid-

Afrikaanse Akademie vir

Wetenskap en Kuns.

Hierdie werk is onder

die Creative Commons

Attribution License

gelisensieer.
Die reduksie van tris( $\beta$-diketonato)mangaan(III) ([Mn( $\beta$-diketonato $\left.\left.)_{3}\right]\right)$ verbindings na tris( $\beta$-diketonato)mangaan(II), asook die oksidasie daarvan tot tris( $\beta$-diketonato) mangaan(IV), is ondersoek met behulp van DFT-metodes. Die akkuraatheid van die voorspelling van die reduksiepotensiaal of oksidasiepotensiaal is baie belangrik vir die bepaling van die potensiaalomvang wat geskik is vir die ontwerp van spesifiek vereiste toepassings. Die DFT-funksionele metode M06 het die eksperimentele reduksiepotensiaal tot ' $n$ hoër vlak van akkuraatheid weergegee, in vergelyking met die M062X en B3LYP metodes. Hierdie studie het ook getoon dat reduksie van verbindings ' $n$ afname in entropie en ook Gibbs vrye energie, in sowel die gasfase as die oplosmiddelfase, veroorsaak het en gevolglik die hoogste waarde vir totale Gibbs reaksie-energie $\left(\Delta \mathrm{G}_{\mathrm{rksie}}\right)$ vir die gereduseerde verbinding getoon het, veral vir dié molekules met sterker elektron-onttrekkende groepe, soos $\mathrm{CF}_{3}$. Dit het gelei tot 'n reduksiepotensiaalverskuiwing na meer positiewe waardes, vir dié verbindings wat $\mathrm{CF}_{3}$ bevat. Hierdie meer positiewe reduksiepotensiaal van verbindings in die teenwoordigheid van sterker elektrononttrekkende groepe het ook ' $n$ skuif na meer positiewe oksidasiepotensiaal tot gevolg gehad. Gevolglik kon die oksidasiepotensiaal gaandeweg nie meer binne die eksperimentele venster vir oplosmiddels waargeneem word nie. Die waardes van die molekulêre elektrostatiese oppervlakpotensiaal (MESP) minima en die MESP atoompotensiaal van die Mn atoom en sy gekoördineerde suurstofatome, dien as goeie beskrywers vir die waargeneemde eksperimentele reduksiepotensiaal en kan ook bydra om die eksperimentele reduksie van toekomstige molekules tot ' $n$ hoë vlak van akkuraatheid te kan voorspel.

Sleutelwoorde: Redokspotensiaal, $\beta$-diketonato, mangaan (III), DFT, MESP

Substituent and isomeric effects on the reduction and oxidation potential of tris( $\beta$ diketonato) manganese (III) complexes: DFT and MESP analysis: The reduction of tris( $\beta$-diketonato)manganese(III) ([Mn( $\beta$-diketonato $\left.\left.)_{3}\right]\right)$ derivatives to tris( $\beta$-diketonato) manganese(II) and their oxidation to tris( $\beta$-diketonato)manganese(IV) was studied using DFT methods. The accuracy of prediction of the reduction potential or oxidation potential is very significant for their customized design, for determining the range of potentials that will be suitable for specific desired applications. The DFT functional method M06 reproduced the experimental reduction potential to a higher level of accuracy compared to M062X and B3LYP. The study also showed that the reduction of the molecules resulted in a decrease in the entropy and the Gibbs free energy of both the gas phase and the solvent phase, consequently yielding the highest value of total Gibbs free energy of reaction $\left(\Delta G_{r x t}\right)$ for the reduced molecule, especially for those molecules containing stronger electron withdrawing groups like $\mathrm{CF}_{3}$. This led to the shifting of the reduction potential of the molecules containing $\mathrm{CF}_{3}$ to more positive values. The more positive the reduction potential of the molecules became in the presence of stronger electron withdrawing groups, the more positive their oxidation potential shifted. This consequently rendered the oxidation potential impossible to be observed within the experimental solvent window. The values of the molecular electrostatic surface potential (MESP) minima and MESP atomic potential of $\mathrm{Mn}$ and coordinating oxygen atoms, served as good descriptors for the observed experimental reduction potential and might also assist in predicting the experimental reduction of further molecules to a high level of accuracy.

Keywords: redox potential, $\beta$-diketonato, manganese (III), DFT, MESP 


\section{Inleiding}

Metaalkomplekse met asetielasetonato-ligande word wyd gebruik as katalisatore, ko-katalisatore, as redoksmedium in kleursensitiewe sonselle (DSSCs) of as elektroliete in enkelmetaal-redoksbatterye (RFB). Die bekendste van die $\left[\mathrm{Mn}(\beta \text {-diketone })_{3}\right]$-reeks komplekse, naamlik tris(asetielasetonato)mangaan(III), kwalifiseer goed vir hierdie toepassings, aangesien dit relatief maklik gereduseer of geoksideer kan word tot sy verwante Mn(II) en Mn(IV) spesies (Gritzner et al., 1979).

$\mathrm{Mn}(\beta \text {-diketonato })_{3}$ toon byvoorbeeld belowende resultate as ' $n$ doeltreffende bestanddeel van die elektroliet in ' $n$ enkelmetaal-redoksbattery (RFB), wat onder meer gebruik kan word vir die storing van groot hoeveelhede energie wat deur windturbines en sonselle geproduseer word (Sleightholme et al., 2011). Onder standaardtoestande is die potensiaallimiet vir elektroliete in oplossing 1.23 V. Aangesien die digtheid van 'n RFB se krag en energie bepaal word deur die selpotensiaal, is voorafinligting oor die redoks-eienskappe en stabiliteit van die elektroliet/ oplosmiddelstelsel (wat in hierdie geval $[\mathrm{Mn}(\beta-$ diketonato) ${ }_{3}$ ] bevat) baie belangrik.

Evaluering van $\left[\mathrm{Mn}(\beta \text {-diketonato })_{3}\right]$-komplekse as redoksmedium in kleursensitiewe sonselle (DSSCs) (Carli et al., 2016; Perera et al., 2014), het getoon dat die $\mathrm{Mn}^{\mathrm{III}} / \mathrm{Mn}^{\mathrm{II}}$ redokspaar betrokke was by die regenereringsproses van die kleurstof (dye). Alhoewel [Mn( $\beta$-diketonato) $\left.{ }_{3}\right]$ minder effektief was as kommersiëel beskikbare sensiteerders, is daar voorgestel dat substitusie van die $\mathrm{CH}_{3}$-groepe deur elektrononttrekkende groepe (bv. $\mathrm{CF}_{3}$ ) op die asetielasetonatoligand, die weg sou baan om mangaan-redokspare te ontwikkel met meer positiewe redokspotensiale, wat mag lei tot DSSCs met hoër oop-stroombaan potensiaalverskil.

Verder het tris(asetielasetonato)mangaan(III) verskillende toepassings as homogene katalisator (Bryant et al., 2002; Dewar en Nakaya, 1968; Khusnutdinov et al., 2002; Magnus et al., 2000; Wang en Chiba, 2009), as katalisator van die drogingsproses van verf (Bouwman en Van Gorkum, 2007; Van Gorkum et al., 2004), as heterogene katalisator (Sodhi en Paul, 2011) of as voorloper van heterogene katalisatore (Kenvin et al., 1991). As katalisator vir die polimerisasie van benzoksazien, is gevind dat vervanging van die $\mathrm{CH}_{3}$-groepe op die asetielasetonaat-ligand deur die elektrononttrekkende $\mathrm{CF}_{3}$-groep, gelei het tot ' $\mathrm{n}$ verhoogde katalitiese aktiwiteit (Sudo et al., 2010).

Daar is aangetoon dat die oksidasie en reduksie-eienskappe van $\mathrm{Mn}(\mathrm{III})$ fyn ingestel kan word in [Mn( $\beta$-diketonato) $\left.{ }_{3}\right]$ verbindings, deur die $\mathrm{CH}_{3}$-groepe op die asetielasetonatoligand te vervang deur substituente met ' $n$ verskeidenheid elektrondonerende of elektrononttrekkende eienskappe. Meer elektrononttrekkende substituente (bv. $\mathrm{CF}_{3}$ ) lei tot ' $\mathrm{n}$ hoër (meer positiewe) redokspotensiaal vir beide die $\mathrm{Mn}^{\mathrm{III}}$ / $\mathrm{Mn}^{\mathrm{II}}$ en $\mathrm{Mn}^{\mathrm{III}} / \mathrm{Mn}^{\mathrm{IV}}$ redokspare van $\left[\mathrm{Mn}(\beta \text {-diketonato })_{3}\right]-$ verbindings (Freitag en Conradie, 2015). Dit was egter nie moontlik om die redokspotensiaal eksperimenteel te meet met sikliese voltammogramme vir die $\mathrm{Mn}^{\mathrm{III}} / \mathrm{Mn}^{\mathrm{IV}}$ redokspaar van komplekse met sterk elektrononttrekkende groepe nie, aangesien hulle waardes buite die eksperimentele venster vir oplosmiddels val (weens die beperking van die waarneembare oplosmiddel-elektrolietkombinasie tydens elektrochemie.) Dit is dus weens bogenoemde redes belangrik om eerder ' $n$ teoretiese manier te vind om betroubare redokspotensiale vir die $\mathrm{Mn}^{\mathrm{III}} / \mathrm{Mn}^{\mathrm{II}}$ en $\mathrm{Mn}^{\mathrm{III}}$ / $\mathrm{Mn}^{\mathrm{IV}}$ redokspare van $\left[\mathrm{Mn}(\beta \text {-diketonato })_{3}\right]$-verbindings akkuraat te bereken.

Hiermee word dus 'n berekeningschemie-ondersoek aangebied om redokspotensiale van $\left[\mathrm{Mn}(\beta \text {-diketonato })_{3}\right]$-komplekse teoreties te bereken, in goeie ooreenstemming met beskikbare eksperimentele resultate vanuit die literatuur (Carli et al., 2016; Freitag en Conradie, 2015), sien Figuur 1. Boonop word angetoon dat die redokspotensiale van tris( $\beta$ diketonato)mangaan(III)-verbindings voorspel kan word vanaf die molekulêre elektrostatiese oppervlakpotensiaal (MESP) van die verbindings. MESP-analise is 'n belangrike metode wat bydra tot die begrip van verskillende chemiese verskynsels, vanaf intermolekulêre interaksies (Remya en Suresh, 2018, 2016) tot verskeie ander chemiese eienskappe (Mohan et al., 2013; Politzer et al., 2001; Politzer en Murray, 2002) soos chemiese bindings, resonansie, chemiese reaktiwiteit, induktiewe effek en voorspelling van molekule se redokspotensiaal (Anjali et al., 2016).

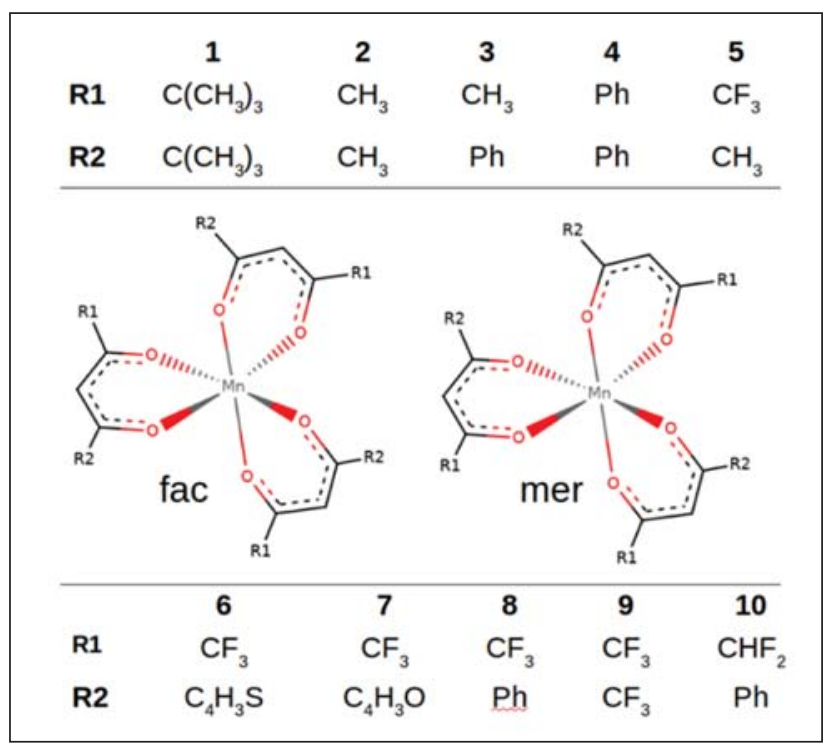

FIGUUR 1: Fac en mer isomere van die [Mn ( $\beta$-diketonato) $)_{3}$-komplekse wat in hierdie studie gebruik is. Verbindings 1, 2, 4 en 9 is simmetries, terwyl 3, 5, $6,7,8$ en 10 onsimmetries gesubstitueer is.

\section{Berekeningsmetodes Berekening van redokspotensiaal}

Die reduksiepotensiale is bereken met behulp van twee verwante vrye energiesiklusse, soos beskryf in ons vorige navorsing (Adeniyi en Conradie, 2019, 2018) en word in Figuur 2 aangetoon.

In die eerste vrye energiesiklus word die reduksiepotensiaal $\left(E_{\mathrm{sel}}\right)$ bereken soos berig in die literatuur (Marenich et al., 2014) deur middel van vergelyking 1 :

$$
\begin{aligned}
& E_{\text {sel }}(v s \text { SHE in } V)=\frac{-\Delta G_{r k s i e}}{n F}-E_{S H E} \quad \ldots 1 \\
& \text { where } \Delta G_{r k s i e}=\Delta G_{\text {gas }}-\Delta \Delta G_{\text {opl.mid }} \\
& \text { and } \Delta \Delta G_{\text {opl.mid }}=\Delta G_{s}\left(M^{-}\right)-\Delta G_{s}(M)
\end{aligned}
$$




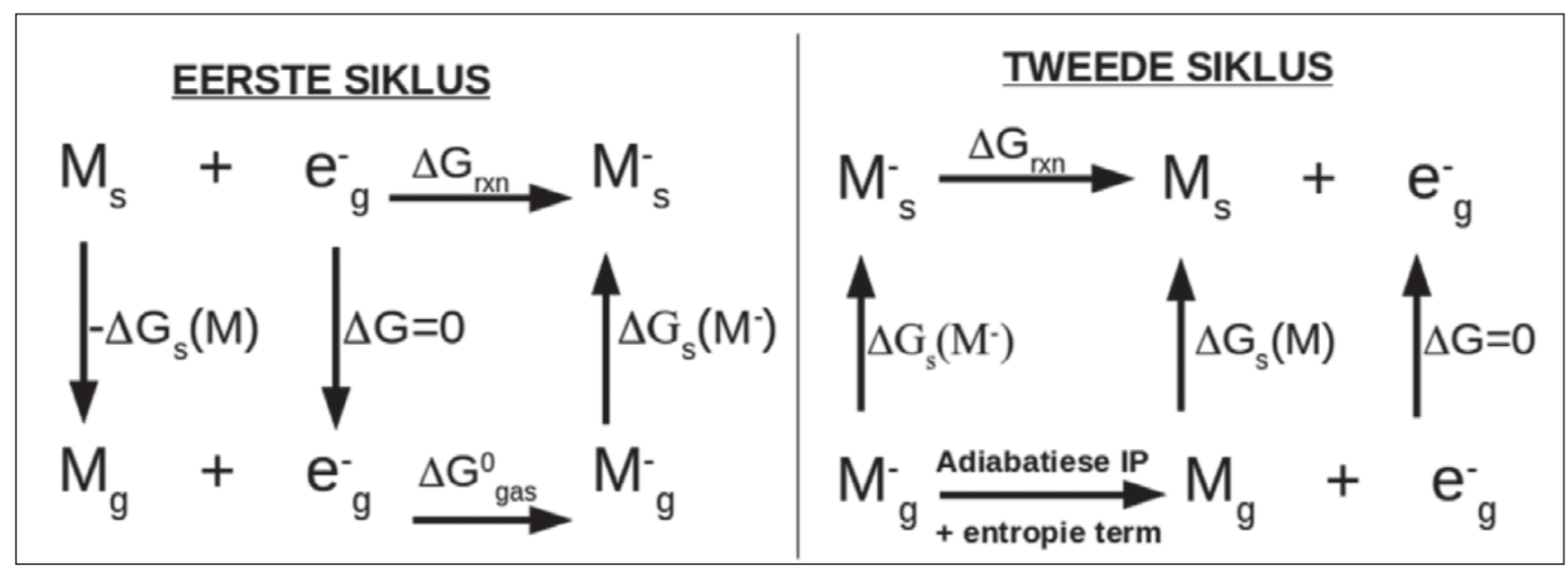

FIGUUR 2: ' $\mathrm{n}$ Skema van die twee vrye energiesiklusse wat gebruik is vir die berekening van die verbindings se redokspotensiaalwaardes $(\mathrm{g}=$ gas, $\mathrm{s}=$ oplosmiddel en $\mathrm{RXN}=$ reaksie)

Die terme $\mathrm{G}_{\mathrm{s}}(\mathrm{M})$ en $\mathrm{G}_{\mathrm{s}}\left(\mathrm{M}^{-}\right)$verteenwoordig onderskeidelik die oplossing se vrye energie van die verbindings se neutrale en gereduseerde toestande.

In die tweede siklus word die reduksiepotensiaalwaardes bereken deur gebruik te maak van die gasfase-berekende adiabatiese ionisasie-energieë (IP) en oplosingsenergieë $\left(\Delta \mathrm{G}_{\mathrm{s}}\right)$, soos berig in die literatuur (Fu et al., 2005), deur middel van vergelyking 2 :

$$
E^{0}(\text { vs NHE in } V)=I P+\frac{1}{23.06}\left\{-T \Delta S+\Delta G_{s}(M)-\Delta G_{s}\left(M^{-}\right)\right\}-E_{N H E} \cdots 2
$$

Aangesien die $\left[\mathrm{Mn}(\beta \text {-diketonato })_{3}\right]$-komplekse se eksperimentele reduksiepotensiaal uit die literatuur bepaal is teenoor die redokspotensiaal van ferroseen $\mathrm{Fc} / \mathrm{Fc}^{+}$as verwysingselektrode (Carli et al., 2016; Freitag en Conradie, 2015), is die waarde van die verwysingspotensiaal in vergelyking 1 ook verander vanaf die standaard waterstofelektrode $\left(E_{\mathrm{SHE}}=4.28 \mathrm{~V}\right)$ as verwysing (Marenich et al., 2014), na die absolute reduksiepotensiaal van $\mathrm{FC}_{\mathrm{C}} /$ $\mathrm{FC}^{+}$in asetonitrieloplossing $(4.980 \mathrm{~V})$ (Namazian et al., 2010). Soortgelyk is die normale waterstofelektrode $\left(E_{\mathrm{NHE}}\right.$ $=4.44 \mathrm{~V}$ ) in vergelyking 2 ook verander na die absolute reduksiepotensiaal van $\mathrm{Fc} / \mathrm{Fc}^{+}$in asetonitrieloplossing (4.980 V) (Namazian et al., 2010).

\section{Berekening van elektronaffiniteit en ionisasie- potensiaal}

Die ionisasiepotensiaal (IP) en elektronaffiniteit (EA) van die molekules word bereken deur:

$$
\begin{array}{ll}
\mathrm{IP}=\mathrm{E}(\text { oks })-\mathrm{E}(\text { neut }) & \ldots .3 \mathrm{a} \\
\mathrm{EA}=\mathrm{E}(\mathrm{red})-\mathrm{E}(\text { neut }) & \ldots .3 \mathrm{~b}
\end{array}
$$

waar E(neut), E(oks) en E(red) die berekende energieë in die gasfase is vir onderskeidelik die neutrale, geoksideerde en gereduseerde toestand van die molekules.

\section{Berekening van die MESP parameters}

Die molekulêre elektrostatiese oppervlakpotensiaal (MESP) waarde, V(r) by punt $r$, word bereken deur die standaardvergelyking,

$$
V(r)=\sum_{A}^{N} \frac{Z_{A}}{\left|r-R_{A}\right|}-\frac{\rho\left(r^{\prime}\right) d^{3} r^{\prime}}{\left|r-r^{\prime}\right|} \quad \ldots 4
$$

waar $Z_{A}$ die lading is op kern $A$ by $R_{A^{\prime}} \rho\left(r^{\prime}\right)$ die elektrondigtheid by punt $r$ en $N$ die totale aantal kerne. Uit die kritieke punte $(\mathrm{CP})$ vir die MESP topologie-analise, is $(3,+3) \mathrm{CP}$ in ooreenstemming met die minimum $\left(\mathrm{V}_{\min }\right)$; $(3,-3)$ is die maksimum $\left(\mathrm{V}_{\text {maks }}\right)$, terwyl $(3,+1)$ en $(3,-1)$ infleksiepunte aandui (Gadre en Shirsat, 2001).

\section{DFT metodes}

Vir alle berekeninge is die multiplisiteit van die neutrale, gereduseerde en geoksideerde vorme van die tris( $\beta$ diketonato)mangaan(III)-komplekse gestel op onderskeidelik 5, 6 en 4, en die geoptimiseerde geometrieë is verkry deur gebruik te maak van die funksionele digtheidsteorie (DFT) se B3LYP metode en die basisstel 6-31+G(df, p), soos geïmplementeer in metode G09 (Frisch et al., 2009). Die energiewaardes van dié geoptimiseerde komplekse wat benut is in die vrye energiesiklusberekeninge, is herbereken deur die DFT-metodes M06/6-311+G(2df,2p) en M062X/6$311+G(2 d f, 2 p)$, en daarna toegepas in die vrye energieberekening, met die nulpuntenergie bereken volgens die B3LYP/6-31+G(df,p) metode. Hierdie funksionale is gekies, aangesien die M06- en M062X-metodes bekendstaan as goeie keuse vir termodinamiese metodes (Zhao en Truhlar, 2006), terwyl die B3LYP metode goeie geometrieë produseer. Die oplossingsenergie is bereken in 'n asetonitriel-oplosmiddelfase, deur gebruik te maak van die oplosbaarheidsmodeldigtheid (SMD) van die polariseerbare kontinuum-model (PCM) (Marenich et al., 2009), wat die nie-homogene Poisson-vergelyking opgelos het deur die integraalvergelykingformule se variante toe te pas. (IEFPCM) (Skyner et al., 2015). 
Die berekening van die molekulêre elektrostatiese oppervlakspotensiaal (MESP) is gedoen deur dieselfde metode B3LYP/6-31+G(df,p) te gebruik as in die optimalisering, en is bereken in die asetonitriel-oplosmiddelfase. Al die MESP-berekeninge is met behulp van die G09-metode uitgevoer (Frisch et al., 2009), terwyl verdere analise van die golffunksieberekeninge verkry is deur Multiwfn ( $\mathrm{Lu}$ en Chen, 2012a, 2012b). Die molekulêre weergawe van die verbindings se MESP iso-oppervlak is gelewer deur sowel vmd (Humphrey et al., 1996) asook Multiwfn (Lu en Chen, 2012a, 2012b) te gebruik.

\section{Data analise}

Die lineêre regressievergelyking $\mathrm{Y}=\mathrm{b}_{0}+\mathrm{b}_{1} \mathrm{X}_{1}$ wat die verband aantoon tussen die berekende eienskappe $\left(X_{1}\right)$ en die eksperimentele reduksiepotensiaal (Y), is afgelei deur middel van die R-statistiese pakket (R-Core-Team, 2018). Die genereerde regressieparameters wat gebruik is om die effektiwiteit of vlak van korrelasie te bepaal, is die afsnit $\left(b_{0}\right)$, helling $\left(b_{1}\right)$, korrelasie $\left(\mathrm{R}^{2}\right)$, F-statistiek, $t$-waardes, P-waarde en die Residuele Standaardfout (RSE). Die korrelasievlak kan as meer optimaal beskou word vir $\mathrm{R}^{2}$ waardes nader aan een, asook baie hoë waardes vir beide die F-statistiek en die t-waardes, gekombineer met ' $n$ laer P-waarde (bv. 0.05). Wanneer die verwantskap bepaal word tussen eksperimentele en berekende waardes, (in hierdie geval deur middel van grafieke van eksperimentele reduksiepotensiaal teenoor berekende reduksiepotensiaal), sal die beste korrelasie van die berekende met eksperimentele waardes bereik wees wanneer helling $b_{1}$ neig na een en afsnit $b_{0}$ neig na nul. Besonderhede van die data-analise van hierdie studie se resultate word gelys in Tabel S2 van die Ondersteunende Materiaal.

\section{Resultate en bespreking}

Van die tien $\left[\mathrm{Mn}(\beta \text {-diketonato })_{3}\right]$-komplekse wat in hierdie studie (Figuur 1) ondersoek is, kan die ses komplekse 3, 5, $6,7,8$ en 10 bestaan as sowel mer-asook fac-isomere. In alle berekeninge is beide die fac-asook mer-isomere van hierdie ses komplekse met asimmetriese R1 en R2 substituente ingesluit, behalwe vir die mer-isomeer van kompleks 7 wat uit hierdie studie uitgesluit is, aangesien die gereduseerde geometrie daarvan nie korrek geoptimaliseer het nie. Vanuit al hierdie komplekse met mer-en fac-isomere, het slegs kompleks 10 se fac-isomeer 'n relatief laer energie gehad (meer stabiel) as sy mer-isomeer, terwyl die merisomere van komplekse 3, 6, 7 en 8 op hulle beurt meer stabiel was (met laer energie) as hulle fac-isomere (Tabel S1). Die maksimum energieverskil tussen die mer- en facisomere was slegs $0,05 \mathrm{eV}$, wat impliseer dat beide die meren $f a c$-isomere eksperimenteel kan bestaan.

\section{Reduksiepotensiaal van die [Mn"'( $\beta$-diketo- nato) $)_{3}$ ] komplekse}

Die akkuraatheid van teoretiese berekeninge van oorgangsmetaalkomplekse se reduksie- en oksidasiepotensiale is baie belangrik vir die spesifieke ontwerp van metaal- komplekse wat bepaalde waardes van reduksie- of oksidasiepotensiale benodig vir spesifieke toepassings. Die eksperimenteel gemete reduksiepotensiale van al tien $\left[\mathrm{Mn}(\beta \text {-diketonato })_{3}\right]$-komplekse in hierdie studie (Figuur 1$)$, is beskikbaar in die literatuur (Carli et al., 2016; Freitag en Conradie, 2015). Die teoretiese berekening van reduksiepotensiale is verkry deur middel van funksionaal B3LYP / 6$31+\mathrm{G}(\mathrm{df}, \mathrm{p})$ vir die geometriese optimisering, berekening van nulpunt-energie en vir die oplossingsenergie. Die gasfase vrye-energie in die termodinamiese siklusse (Figuur 2) is bereken deur teoreties-berekende nulpunt-energie en die berekende energiewaardes verkry deur die M06/6$311+G(2 d f, 2 p), \quad M 062 X / 6-311+G(2 d f, 2 p)$ en B3LYP/6$31+\mathrm{G}(\mathrm{df}, \mathrm{p})$ metodes. Beide vrye-energie siklusse 1 en 2 (Figuur2)hetdieeksperimenteel-gemetereduksiepotensiale tot ' $\mathrm{n}$ hoë vlak van akkuraatheid weergegee, met waardes vir $\mathrm{R}^{2}>0.96$, sien Tabel S2 a en $\mathrm{b}$.

Vanuit die drie DFT-metodes (B3LYP, M06 en M062X) wat gebruik is om die reduksiepotensiale van die $\mathrm{Mn}^{\mathrm{III}} / \mathrm{Mn}^{\mathrm{II}}$ redokspaar van komplekse 1 - 10 te bereken, het metode M06 ' $n$ beter weergawe van die eksperimentele waardes gegee vergeleke met M062X wat die waardes oorskat het, terwyl B3LYP hulle onderskat het (Tabel 1, Figuur 3a). Die meeste van die eksperimentele reduksiepotensiale is tot 'n beduidende vlak van akkuraatheid herproduseer met toepassing van die M06-funksionaal, behalwe vir kompleks 1 wat ' $n$ beduidende afwyking van die eksperimentele waardes getoon het (Figuur 3). Hierdie afwyking kan moontlik daaraan toegeskryf word dat die eksperimentele reduksiepotensiaal van kompleks 1 in dichloormetaan as oplosmiddel gemeet is, terwyl die ander komplekse 2 - 10 almal in asetonitriel gemeet is. Alle teoreties-berekende reduksiepotensiale is ook verkry met asetonitriel as oplosmiddel in die vrye-energie siklusse uit Figuur 2. Wanneer eksperimentele en teoretiese redokswaardes vergelyk word, word eksperimentele waardes wat onder dieselfde eksperimentele toestande verkry is, egter verkies. Herberekening van kompleks 1 se reduksiepotensiaal deur middel van die M06-funksionaal en met dichloormetaan as oplosmiddel in plaas van asetonitriel, het ' $\mathrm{n}$ effens beter teoreties berekende waarde gelewer in vergelyking met die eksperimenteel bepaalde waarde $(-0.964 \mathrm{~V})$, naamlik -0.737 en $-0.830 \mathrm{~V}$ onderskeidelik vir die eerste en tweede termodinamiese siklusse (Figuur 2). Die eerste termodinamiese siklus het die eksperimentele resultate beter herproduseer toe die M06-funksioneel gebruik is (Figuur 3a), met ' $n$ kleinste waarde vir gemiddelde absolute afwyking (MAD) van $0.102 \mathrm{eV}$ (verkry deur die simmetries-gesubstitueerde komplekse te benut saam met die fac-isomere van die onsimmetriese komplekse). Die MAD-waarde by die gebruik van die tweede termodinamiese siklus was $0.145 \mathrm{eV}$ (Tabel 1). Alhoewel die teoreties-berekende reduksiepotensiaal effens afwyk van die eksperimentele, was die korrelasie tussen hierdie waardes steeds baie hoog. Die korrelasieresultate van die M062X $\left(R^{2}=0.973\right.$ tot 0.975$)$ en B3LYP $\left(R^{2}=0.961\right.$ tot $0.966)$ metodes was ewe hoog as dié van metode M06 $\left(R^{2}\right.$ 
$=0.970$ to 0.973 ), selfs al het hulle ' $n$ groter afwyking vanaf eksperimentele waardes getoon in vergelyking met metode M06 (Tabel S2 a en b, Figuur S1 a en b). Die Y-afsnit van die lineêre regressievergelyking tussen die eksperimentele en die berekende reduksiepotensiale met behulp van die M06-metode, het geneig na waardes van nul (0.5 en 0.035 $\mathrm{eV}$ onderskeidelik vir die fac-en mer- isomere), wat 'n goeie vlak van akkuraatheid aandui. ' $n$ Groter afwyking is egter verkry vir funksionale M062X (met negatiewe waardes, wat beteken die reduksiepotensiaal is oorskat) en B3LYP (met positiewe waardes wat beteken die reduksiepotensiale is onderskat) (Tabel S2 a en b).

Terwyl die effek van elektrononttrekkende substituente R1 en $\mathrm{R} 2$ op die $\beta$-diketonato-ligand van $\left[\mathrm{Mn}(\beta \text {-diketonato })_{3}\right]$ komplekse 1 - 10 (Figuur 1 ) reeds duidelik was vanaf die eksperimentele reduksiepotensiale (wat ook herproduseer is in die teoretiese berekening), het die teoretiese metode bykomende insig verleen in die effekte wat isomere het op die verandering in termodinamiese eienskappe van die gemete reduksiepotensiale. Die waardes van die teoretiesberekende verandering in termodinamiese parameters, word in Tabel S3 gelys.

Daar was slegs ' $n$ klein verskil in die waardes van die reduksiepotensiale van die fac- en mer-isomere, sien Tabel 1. Die resultate van die drie funksionale M06, M062X en B3LYP, in kombinasie met òf die eerste òf die tweede vrye-energie siklus (Figuur 2), het duidelik getoon dat die berekende reduksiepotensiale van komplekse 3 en 8 se merisomere groter (meer positief) was as vir die fac-isomere. Die relatiewe verskil in reduksiepotensiale van onsimmetriese komplekse 5, 6 en 10 se mer- en fac-isomere was afhanklik van die metode wat toegepas is. Funksionaal M06 saam met die eerste termodinamiese siklus het die eksperimentele resultate die beste herproduseer. Alhoewel kompleks 5 se berekende reduksiepotensiaal ook groter (meer positief) was vir die mer-isomeer in vergelyking met die fac-isomeer, was die omgekeerde die geval vir komplekse 6 en 10.

Dit was duidelik vanuit beide eksperimentele en teoretiese waardes vir reduksiepotensiaal dat 'n kombinasie van twee simmetriese, sterk elektrondonerdende - $\mathrm{C}\left(\mathrm{CH}_{3}\right)_{3}$ substituente per $\beta$-diketonato-ligand, soos in kompleks 1 , 'n meer negatiewe reduksiewaarde tot gevolg gehad het. In teenstelling daarmee het twee simmetriese sterk elektrononttrekkende $\mathrm{CF}_{3}$-substituente per $\beta$-diketonato ligand, soos in kompleks 9, gelei tot ' $n$ meer positiewe reduksiewaarde (Figuur 3 en Tabel 1). Die asimmetriese kombinasie van beide 'n elektrononttrekkende en 'n elektrondonerende groep, soos in komplekse 5 en 10, het 'n hoër en minder negatiewe reduksiepotensiaal gelewer, en sodoende die reduksie-aktiwiteit van daardie komplekse verhoog. Die verandering in termodinamiese eienskappe

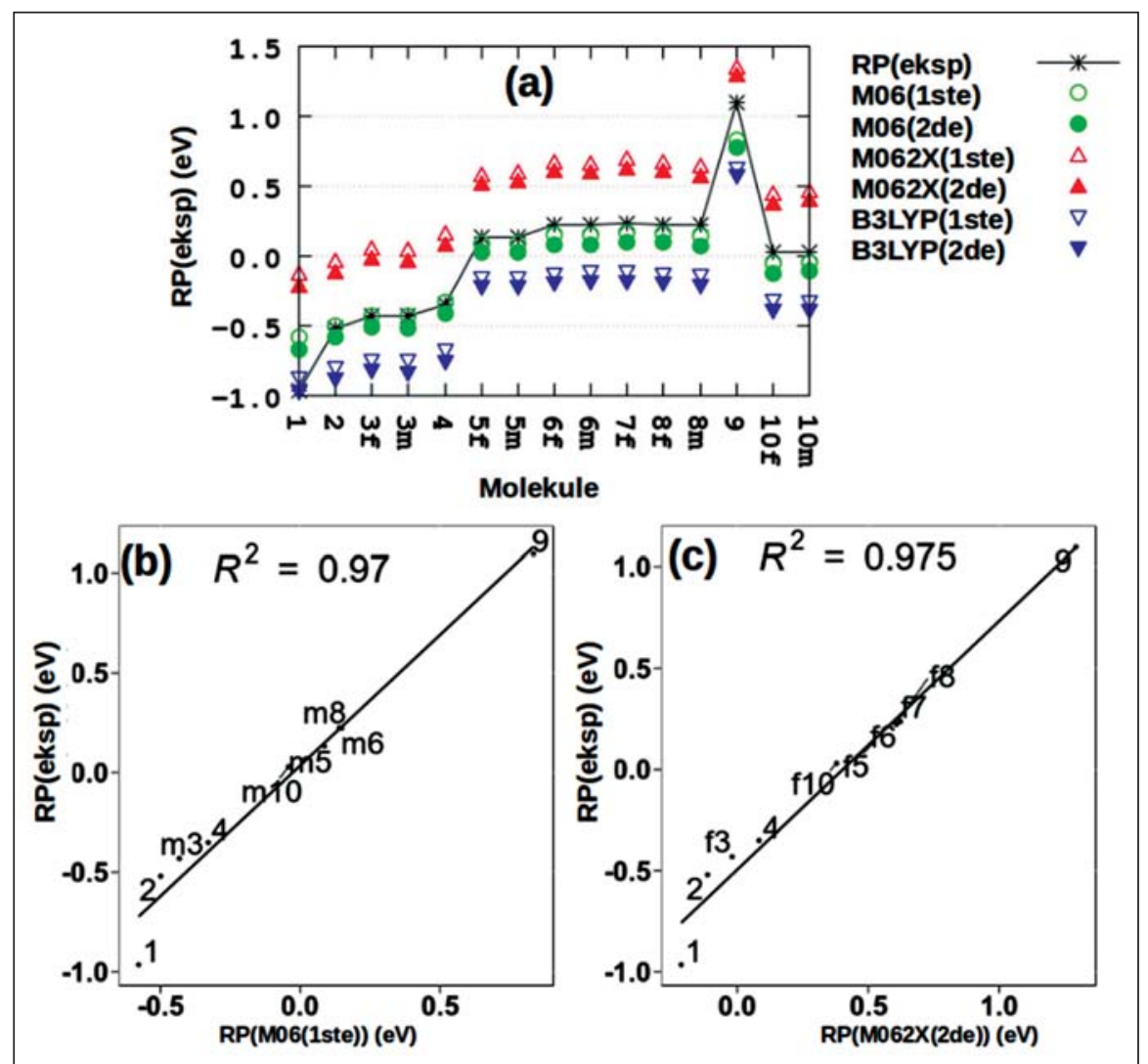

FIGUUR 3: Grafieke van (a) die eksperimentele reduksiepotensiaal (RP(eksp)) van die Mn'"/Mn" redokspaar van [Mn( $\beta$-diketonato) ${ }_{3}$-komplekse 1 - 10, teenoor die teoretiese reduksiepotensiaal bereken deur metodes M06, M062X en B3LYP, met beide die eerste en tweede vrye energie-siklus; Korrelasie van eksperimentele reduksiepotensiaal met (b) die berekende waardes van sowel die simmetries gesubstitueerde komplekse 1, 2, 4 en 9, asook as die mer-isomere van die onsimmetriese komplekse 3, 5, 6, 7, 8 en 10, bereken volgens metode M06 met die eerste energiesiklus; en ook korrelasie met (c) berekende waardes van die simmetries gesubstitueerde komplekse 1, 2, 4 en 9, sowel as die fac-isomere van onsimmetriese komplekse 3, 5, 6, 7, 8 en 10, bereken volgens metode M062X met die tweede energiesiklus. Alle reduksiepotensiale is in $\mathrm{V}$ vs $\mathrm{Fc} / \mathrm{Fc}^{+}$. 
TABEL 1: Die teoretiese reduksiepotensiaal van die $\mathrm{Mn}$ "'I/Mn" redokspaar van [Mn(6-diketonato) ${ }_{3}$-komplekse 1 - 10, bereken met behulp van funksionale $\mathrm{M} 06$, M062X en B3LYP volgens beide die eerste asook tweede termodinamiese siklusse, vergelyk met die eksperimentele reduksiepotensiaal (in die eerste kolom). Die gemiddelde absolute afwyking (GAD hier aangetoon as MAD) is bepaal deur die simmetries gesubstitueerde molekules se waardes te vergelyk saam met òf die meròf die fac-isomere van die onsimmetries gesubstitueerde verbindings, soos aangedui. Alle reduksiepotensiale is in $\mathrm{V} v s \mathrm{Fc} / \mathrm{Fc}^{+}$.

\begin{tabular}{|c|c|c|c|c|c|c|c|}
\hline & RP(eksp) & M06(1ste) & M06(2de) & M062X(1ste) & M062X(2de) & B3LYP(1ste) & B3LYP(2de) \\
\hline 1 & -0.964 & -0.578 & -0.671 & -0.122 & -0.215 & -0.877 & -0.970 \\
\hline 2 & -0.520 & -0.499 & -0.576 & -0.038 & -0.114 & -0.806 & -0.883 \\
\hline $3 f$ & -0.431 & -0.431 & -0.505 & 0.053 & -0.020 & -0.747 & -0.820 \\
\hline $3 m$ & -0.431 & -0.432 & -0.515 & 0.049 & -0.034 & -0.754 & -0.837 \\
\hline 4 & -0.351 & -0.329 & -0.408 & 0.162 & 0.083 & -0.676 & -0.755 \\
\hline $5 f$ & 0.132 & 0.090 & 0.027 & 0.583 & 0.520 & -0.160 & -0.223 \\
\hline $5 m$ & 0.132 & 0.087 & 0.023 & 0.595 & 0.532 & -0.164 & -0.227 \\
\hline $6 f$ & 0.223 & 0.148 & 0.085 & 0.671 & 0.608 & -0.134 & -0.197 \\
\hline $6 m$ & 0.223 & 0.149 & 0.084 & 0.661 & 0.595 & -0.118 & -0.184 \\
\hline $7 f$ & 0.236 & 0.171 & 0.099 & 0.695 & 0.623 & -0.116 & -0.187 \\
\hline $8 f$ & 0.225 & 0.161 & 0.098 & 0.669 & 0.606 & -0.134 & -0.197 \\
\hline $8 m$ & 0.225 & 0.140 & 0.069 & 0.645 & 0.574 & -0.142 & -0.213 \\
\hline 9 & 1.095 & 0.835 & 0.780 & 1.349 & 1.294 & 0.627 & 0.572 \\
\hline $10 f$ & 0.030 & -0.051 & -0.122 & 0.450 & 0.379 & -0.320 & -0.391 \\
\hline $10 \mathrm{~m}$ & 0.030 & -0.041 & -0.108 & 0.465 & 0.398 & -0.327 & -0.394 \\
\hline MAD(fac) & & 0.102 & 0.145 & 0.480 & 0.409 & 0.319 & 0.373 \\
\hline $\mathrm{MAD}$ (mer) & & 0.107 & 0.150 & 0.481 & 0.408 & 0.317 & 0.370 \\
\hline
\end{tabular}

vanaf die neutrale na gereduseerde toestand word in Tabel S3 gelys. 'n Afname in entropie asook Gibbs vrye-energie, in beide die gasfase as die oplosmiddelfase, is waargeneem vanaf die neutrale toestand na die gereduseerde toestand, wat gevolglik gelei het tot'n gunstige totale termodinamiese reaksie Gibbs vrye-energie $\left(\Delta \mathrm{G}_{\mathrm{rksie}}\right)$ vir die reduksie van verbindings. Kompleks 9 met die hoogste, mees positiewe reduksiepotensiaal, was ook geassosieer met die hoogste waarde van $\Delta \mathrm{G}_{\mathrm{rksie}}$ maar met die kleinste verandering in die Gibbs vrye-energie van oplosbaarheid.

\section{Oksidasiepotensiaal van die [Mn"'( $\beta$-diketo- nato) $)_{3}$ komplekse}

Die $\mathrm{Mn}^{\mathrm{III}} / \mathrm{Mn}^{\mathrm{IV}}$-redokspaar se eksperimentele oksidasiepotensiale wat beskikbaar was in die literatuur (Carli et al., 2016; Freitag en Conradie, 2015), asook die teoretiesberekende waardes deur middel van die DFT funksionaal M06, word in Tabel 2 aangetoon. Die berekeningschemie het die verbindings se beskikbare eksperimentele oksidasiepotensiale teoreties gereproduseer tot ' $n$ baie hoë vlak van akkuraatheid, vir beide die eerste en tweede termodinamiese siklusse $(\mathrm{MAD}=0.089$ en 0.054 ), deur die resultate te neem van al die simmetries gesubstitueerde molekules saam met die onsimmetriese fac-isomere. Soortgelyk soos tydens berekening van die reduksiepotensiale, is die grootste afwyking vanaf eksperimentele oksidasiepotensiaal weereens verkry vir kompleks 1 , wat verklaar kan word deur die verskillende eksperimentele toestande wat toegepas is vir kompleks 1 (sien hierbo), in vergelyking met die ander molekules.

Tydens hierdie studie was die teoretiese berekening en gevolglike korrelasie met die beskikbare eksperimentele oksidasiepotensiale slegs moontlik vir verbindings 1-4 en 10. Die waardes vir die oksidasiepotensiale van die ander verbindings (5-9) was nie beskikbaar in die literatuur en meestal nie eksperimenteel meetbaar binne die eksperimentele venster vir oplosmiddels nie, maar kon wel deur teoretiese berekeninge verkry word. Die teenwoordigheid van $\mathrm{CF}_{3}$ in verbindings 5 - 9 het 'n baie groter invloed op hulle oksidasiepotensiale gehad as groep $\mathrm{CHF}_{2}$ in kompleks 10, wat gelei het tot ooreenkomstig hoër oksidasiepotensiale vir komplekse 5 - 9, en wat dus oksidasie van hierdie verbindings moeiliker maak. Die hoër teoreties-berekende oksidasiepotensiale vir komplekse 5 - 9 verklaar ook waarom hierdie oksidasiepotensiale nie eksperimenteel gemeet kan word in $\mathrm{CH}_{3} \mathrm{CN}$ nie, aangesien daar ' $\mathrm{n}$ boonste waarneembare limiet van $\mathrm{ca} .1 .1 \mathrm{~V}$ vs $\mathrm{Fc} / \mathrm{Fc}^{+}$ in $\mathrm{CH}_{3} \mathrm{CN}$ bestaan.

Uitstekende korrelasie is egter verkry tussen die eksperimentele reduksiepotensiaal van die verbindings en die teoretiese oksidasiepotensiaal, deur sowel gebruik te maak van die eerste asook tweede termodinamiese siklus (Figuur 4). Die berekende oksidasiepotensiaal was direk eweredig aan die eksperimenteelgemete reduksiepotensiaal. Hierdie verwantskap was volgens verwagting, aangesien die verskil in redokspotensiale tussen twee opeenvolgende redoksprosesse in ' $n$ reeks verwante molekules oor die algemeen binne 'n nou gebied val. Byvoorbeeld, vir Ru(III)-verbindings, was die gemiddelde verskil in redokspotensiale tussen die twee opeenvolgende redoksprosesse se twee $\mathrm{Ru}^{\mathrm{III}} / \mathrm{Ru}^{\mathrm{II}}$ and $\mathrm{Ru} \mathrm{u}^{\mathrm{III}} / \mathrm{Ru}^{\mathrm{IV}}$ redokspare $1.2 \mathrm{~V}$ tot $1.7 \mathrm{~V}$ (Bag et al., 1988; Chattopadhyay et al., 1990; Cornioley-Deuschel en Von Zelewsky, 1987; Eskelinen et al., 2005; Holligan et al., 1992; Lahiri et al., 1987; Rillema en Jones, 1979; Yang et al., 1993). In hierdie studie was die eksperimenteel gemete verskil in redokspotensiale tussen die twee $\mathrm{Mn}^{\mathrm{III}} / \mathrm{Mn}^{\mathrm{II}}$ en $\mathrm{Mn}^{\mathrm{III}} / \mathrm{Mn}^{\mathrm{IV}}$ redokspare van [Mn( $\beta$-diketonato $)_{3}$ ] verbindings 0.9-1.2 V. Gevolglik het kompleks 1 met die mees negatiewe reduksiepotensiaal (-0.964 V vs Fc/ $\mathrm{Fc}^{+}$eksperimenteel) ook die laagste oksidasiepotensiaalwaarde $\left(0.291 \mathrm{~V}\right.$ vs $\mathrm{Fc} / \mathrm{Fc}^{+}$ eksperimenteel) gehad, terwyl kompleks 9 met die mees positiewe reduksiepotensiaal $\left(1.095 \mathrm{~V}\right.$ vs $\mathrm{Fc} / \mathrm{Fc}^{+}$eksperimenteel) ook die hoogste oksidasiepotensiaal getoon het $(2.1 \mathrm{~V}$ vs $\mathrm{Fc} / \mathrm{Fc}^{+} \mathrm{M} 06$ bereken). 

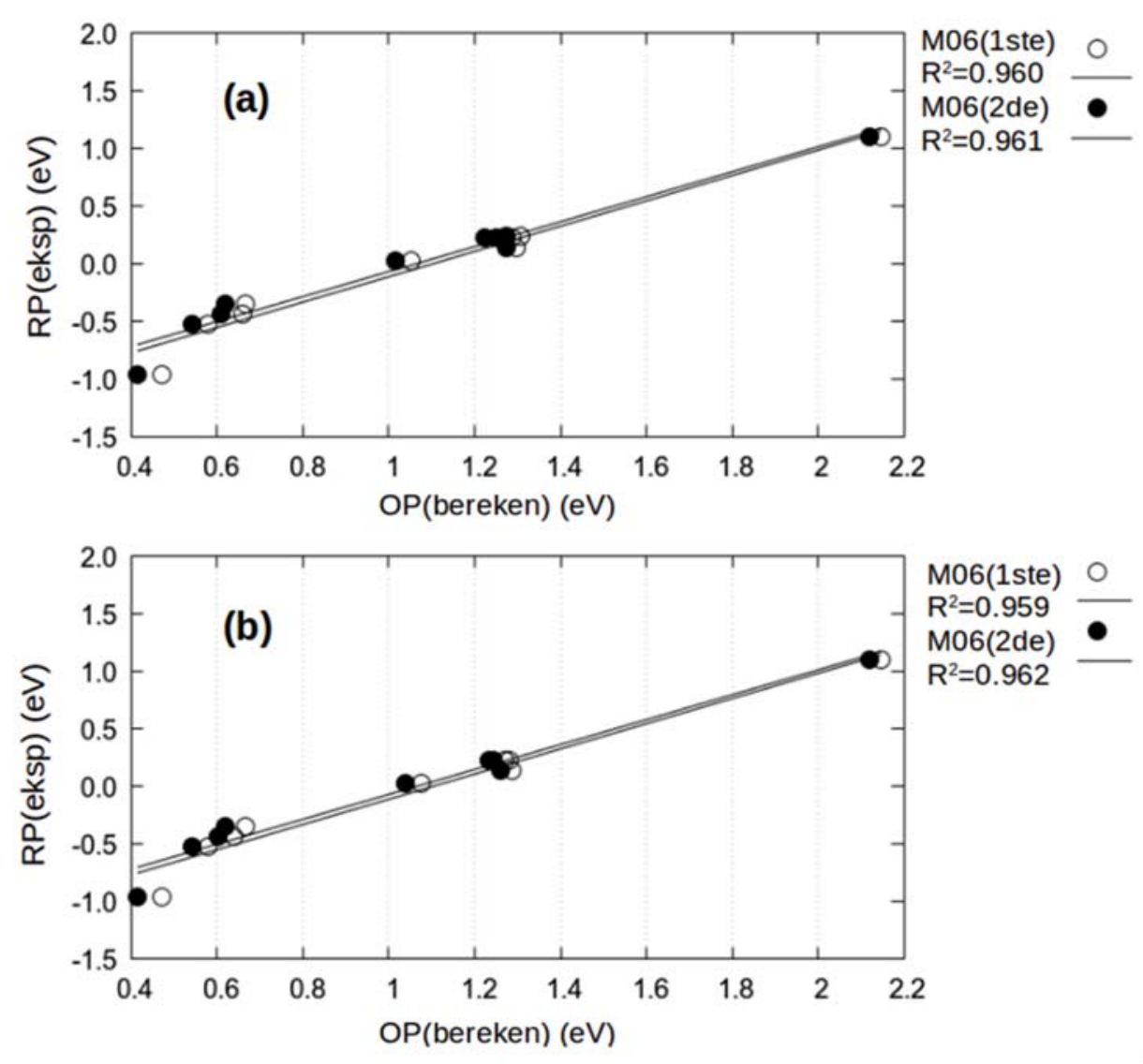

FIGUUR 4: Korrelasie van die Mn"'/Mn" redokspaar se eksperimentele reduksiepotensiaal, RP(exp), met die $\mathrm{Mn}^{\text {"I'/Mn }}{ }^{\mathrm{IV}}$ redokspaar se berekende oksiedasiepotensiaal, $\mathrm{OP}($ bereken), van komplekse 1 - 10, vir al die simmetries-gesubstitueerde komplekse saam met (a) eerstens die fac-isomere in die eerste grafiek en (b) daarna met

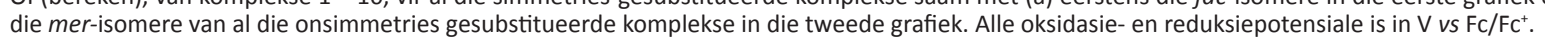

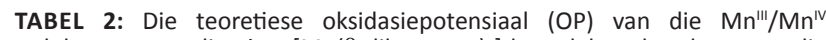
redokspaar van die tien $\left[\mathrm{Mn}(\beta \text {-diketonato })_{3}\right]$-komplekse, bereken met die M06-funksionaal vir beide die eerste en tweede termodinamiese siklusse. Alle oksidasiepotensiale is in $\mathrm{V}$ vs $\mathrm{Fc} / \mathrm{Fc}^{+}$.

\begin{tabular}{cccc}
\hline & OP(eksp) & OP(M06(1ste)) & OP(M06(2de)) \\
\hline 1 & 0.291 & 0.472 & 0.414 \\
2 & 0.571 & 0.579 & 0.542 \\
$3 f$ & 0.593 & 0.658 & 0.607 \\
$3 \mathrm{~m}$ & & 0.639 & 0.601 \\
4 & 0.614 & 0.665 & 0.617 \\
$5 f$ & & 1.298 & 1.273 \\
$5 \mathrm{~m}$ & & 1.287 & 1.260 \\
$6 \mathrm{f}$ & & 1.286 & 1.250 \\
$6 \mathrm{~m}$ & & 1.269 & 1.235 \\
$7 f$ & 1.306 & 1.275 \\
$7 \mathrm{~m}$ & & 1.290 & 1.249 \\
$8 \mathrm{f}$ & & 1.269 & 1.223 \\
$8 \mathrm{~m}$ & & 1.281 & 1.243 \\
9 & & 2.147 & 2.120 \\
$10 f$ & & 1.053 & 1.014 \\
$10 \mathrm{~m}$ & $0.914^{\mathrm{a}}$ & 1.075 & 1.039 \\
\hline MAD & & $\mathbf{0 . 0 8 9}$ & $\mathbf{0 . 0 5 4}$ \\
\hline
\end{tabular}

${ }^{a}$ Eksperimentele OP was nie toegeken aan $10 \mathrm{f}$ of $10 \mathrm{~m}$ nie.

\section{Elektron-affiniteit en ionisasie-potensiaal van

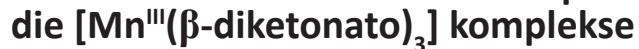

Die waardes van die elektronaffiniteite (EA) is tydens die reduksie-reaksie van die verbindings bereken, deur middel van funksionale M06, M062X en B3LYP (Tabel 3), terwyl hul ooreenstemmende ionisasiepotensiale (IP) tydens die oksidasiereaksie bereken is deur funksionaal M06. Soos verwag, het die komplekse met $\mathrm{CF}_{3}$-substituente die hoogste waardes vir elektronaffiniteit getoon, veral kompleks 9 met twee $\mathrm{CF}_{3}$-substituente op elke $\beta$-diketonato-ligand. Die $\mathrm{CHF}_{2}$-groep het ' $\mathrm{n}$ kleiner effek op elektronaffiniteit gehad as die $\mathrm{CF}_{3}$-groep, wat impliseer dat verbindings met die sterk elektrononttrekkende $\mathrm{CF}_{3}$-groepe ook die grootste affiniteit vir elektrone het. Dieselfde patroon is waargeneem vir ionisasiepotensiale, waar kompleks 9 met twee $\mathrm{CF}_{3}$-substituente op elke $\beta$-diketonato-ligand die hoogste oksidasiepotensiaalwaarde gelewer het, wat impliseer dat kompleks 9 die moeilikste sal wees om te oksideer van komplekse 1 - 10.

Daar was 'n hoë vlak van korrelasie tussen die komplekse se eksperimentele reduksiepotensiaal (selpotensiaal benodig (in V), om 'n elektron by die verbinding te voeg) en die berekende elektronaffiniteit (hoeveelheid energie vrygestel (in eV), wanneer'n elektron bygevoeg word in die gasfase), soos getoon deur $\mathrm{R}^{2}$-waardes baie naby mekaar, van 0.927 tot 0.935 (Figuur S1 (c) en (d), Tabel S2 (c) en (d)), afhangende van die keuse van isomere en berekeningsfunksionale. Elektronaffiniteit was direk eweredig met die eksperimenteel-gemete reduksiepotensiale. Die berekende elektronaffiniteite het ook ' $n$ redelike korrelasie getoon met die berekende ionisasiepotensiaal (met $R^{2}=0.876$ tot 0.893 , 
TABEL 3: Die ionisasiepotensiaal (IP) en elektronaffiniteit (EA) van die komplekse in eV.

\begin{tabular}{ccccc}
\hline & EA(M06) & EA(M062X) & EA(B3LYP) & IP(M06) \\
\hline 1 & -2.658 & -3.114 & -2.359 & 6.495 \\
2 & -2.519 & -2.980 & -2.211 & 6.724 \\
$3 f$ & -2.726 & -3.210 & -2.410 & 6.551 \\
$3 \mathrm{~m}$ & -2.720 & -3.201 & -2.398 & 6.578 \\
4 & -2.900 & -3.391 & -2.553 & 6.464 \\
$5 f$ & -3.516 & -4.009 & -3.266 & 7.755 \\
$5 \mathrm{~m}$ & -3.500 & -4.009 & -3.250 & 7.775 \\
$6 \mathrm{f}$ & -3.570 & -4.093 & -3.288 & 7.298 \\
$6 \mathrm{~m}$ & -3.538 & -4.050 & -3.270 & 7.319 \\
$7 \mathrm{f}$ & -3.540 & -4.064 & -3.254 & 7.332 \\
$8 \mathrm{f}$ & -3.613 & -4.121 & -3.318 & 7.358 \\
$8 \mathrm{~m}$ & -3.580 & -4.085 & -3.298 & 7.389 \\
9 & -4.561 & -5.075 & -4.353 & 8.834 \\
$10 f$ & -3.364 & -3.865 & -3.095 & 7.182 \\
$10 \mathrm{~m}$ & -3.398 & -3.904 & -3.113 & 7.155 \\
\hline
\end{tabular}

afhangende van die funksionale en metodes, Figuur S2). Hierdie waarneming stem ooreen met die korrelasie tussen die molekules se eksperimentele reduksiepotensiaal en berekende oksidasiepotensiaal (Figuur 4).

\section{Molekulêre elektrostatiese potensiaal (MESP) van die [Mn"'( $\beta$-diketonato $\left.)_{3}\right]$ komplekse}

MESP-analises kan wyd toegepas word, van 'n maatstaaf om reaktiwiteit te beskryf, tot die bepaling van stabiliteit van chemiese asook biologiese stelsels (Anjali en Suresh, 2018; Remya en Suresh, 2018). Tipiese MESP-parameters, soos atoompotensiaal $\left(\mathrm{V}_{\text {atom }}\right)$ en minimumpotensiaal $\left(\mathrm{V}_{\text {min }}\right)$, kan suksesvol toegepas word om die totale elektroniese effek van ligande (eeL) te bepaal en reduksiepotensiale van verbindings te voorspel (Anjali et al., 2016; Anjali en Suresh, 2018).

Die berekende waardes van die MESP-minima $\left(\mathrm{V}_{\min }\right)$, die elektrostatiese potensiaal van die Mn-atoom $\left(\mathrm{V}_{\mathrm{Mn}}\right)$, die laagste waarde (aangedui deur l) en die hoogste waarde (aangedui deur h) van die koördineerde O-atome se elektrostatiese potensiaal, word in Tabel 4 getoon, vir beide die neutrale en gereduseerde toestand van die verbindings. Vir al die berekende MESP-parameters was $\mathrm{V}_{\mathrm{Mn}}$ se waarde altyd hoër as $\mathrm{V}_{\mathrm{O}}$ en $\mathrm{V}_{\text {min }}$. Kompleks 9 met twee $\mathrm{CF}_{3}$-groepe per $\beta$-diketonato-ligand, het die hoogste waardes gehad vir die berekende MESP-parameters, gevolg deur dié komplekse 5 tot 8 met elk een $\mathrm{CF}_{3}$-groep per $\beta$-diketonato-ligand. Hierdie MESP-resultate het, net soos by die berekende EA-, IP-, reduksie- en oksidasiepotensiale getoon dat die $\mathrm{CF}_{3}$-groep 'n sterker invloed op die verbindings se MESPparameters het as die $\mathrm{CHF}_{2}$-groep in kompleks 10 . Die teenwoordigheid van die sterk elektrononttrekkende $\mathrm{CF}_{3}$ groep het gelei tot ' $n$ minder negatiewe (kleiner absolute waarde) MESP-parameter. Die MESP-parameters van die mer-isomere was minder negatief as hul ooreenstemmende fac-isomere (Tabel 4). Verder was die MESP-parameters vir die verbindings se neutrale toestand duidelik meer negatief (groter absolute waarde), relatief tot hulle gereduseerde toestand. Die voorstelling van die $\mathrm{V}_{\min }$ - en $\mathrm{V}_{\mathrm{Mn}}$-waardes vir komplekse 2, 9 en 10 (beide 10 fac en 10mer) word in Figuur 5 getoon. Dit is duidelik dat $\mathrm{V}_{\text {min }}$ van elke molekuul tussen twee suurstofatome van twee verskillende koördineerde ligande geleë is, verkieslik òf naaste aan 'n kombinasie van sterk elektrononttrekkende en elektrondonerende groepe, soos in 10 mer (aan die kant met beide $\mathrm{CF}_{3}$ en Ph-substituent), òf naaste aan 'n kombinsasie van twee elektrononttrekkende groepe, soos in $10 \mathrm{fac}$ (aan die kant met twee $\mathrm{CF}_{3}$-substituente) (sien Figuur 5).

Die lineêre regressie-vergelykings word hieronder gegee en verder opgesom in Tabel S2 van die Ondersteunende Materiaal. Die vergelykings is uitgedruk in terme van relatiewe waardes van $\mathrm{V}_{\text {min' }}, \mathrm{V}_{\mathrm{Mn}}$ en $\mathrm{V}_{\mathrm{O}^{\prime}}$, naamlik $\Delta \mathrm{V}_{\text {min }}, \Delta \mathrm{V}_{\mathrm{Mn}}$ en $\Delta \mathrm{V}_{\mathrm{O}^{\prime}}$, wat bereken is deur die waardes van kompleks 2 (met slegs $\mathrm{CH}_{3}$-groepe op die $\beta$-diketonato-ligand as verwysingsmolekuul), af te trek van die ooreenkomstige waardes van elk van die ander komplekse. Van al die regressie-passings is die beste korrelasies, gebaseer op regressie-parameters vanaf Tabel S2 (e) - (j), verkry wanneer die simmetriese asook die mer-isomere van die onsimmetries gesubstitueerde komplekse benut is, deur hulle eksperimentele reduksiepotensiale te plot teenoor die MESP-parameters van hulle gereduseerde toestand (aangedui deur ${ }^{*}$ op die tabel). Voorspelling van die eksperimentele reduksiepotensiaal vanaf die beste passing, vanaf waardes $\Delta \mathrm{V}_{*_{\text {min }}}($ mer $), \Delta \mathrm{V}_{*^{*} \mathrm{Mn}}($ mer $)$ en $\Delta \mathrm{V}_{*{ }_{*} \mathrm{O}}($ mer $)$, lewer die volgende lineêre regressie-vergelykings:

$$
\begin{aligned}
& \mathrm{RP}_{\text {voorspel }}\left(\Delta \mathrm{V}_{*_{\text {min }}}\right)=-0.479+0.036^{*}\left(\Delta \mathrm{V}_{*_{\text {min }}}\right) \quad \mathrm{R}^{2}=0.922 \quad \ldots 5 \mathrm{a} \\
& \mathrm{RP}_{\text {voorspel }}\left(\Delta \mathrm{V}_{{ }^{*} \mathrm{Mn}}\right)=-0.602+14.99^{*}\left(\Delta \mathrm{V}^{{ }^{*}{ }^{\text {min }} \text { Mn }}\right) \quad \mathrm{R}^{2}=0.983 \quad \ldots .5 \mathrm{~b} \\
& \mathrm{RP}_{\text {voorspel }}\left(\Delta \mathrm{V}_{* \text { * } \mathrm{O}}\right)=-0.494+15.781^{*}\left(\Delta \mathrm{V}_{* \text { * } \mathrm{O}}\right) \quad \mathrm{R}^{2}=0.988 \quad \ldots 5 \mathrm{c}
\end{aligned}
$$

Grafiekevir diekorrelasievan die teoreties berekendeMESPparameters met die eksperimentele reduksiepotensiaal word in Figuur 6 getoon, wat ' $n$ beduidende korrelasie aandui. Die waardes van die voorspelde reduksiepotensiaal $\left(\mathrm{RP}_{\text {voorspel }}\right)$, soos verkry deur die drie vergelykings (5a-5c) hierbo, word in Tabel 4 aangetoon. Dit volg vanuit die MAD-waardes dat die voorspellings vanaf parameters $\Delta \mathrm{V}_{*_{\mathrm{Mn}}}(0.051)$ en $\Delta \mathrm{V}_{*_{\mathrm{IO}}}(0.053)$ die eksperimentele waardes die beste weergee het in vergelyking met $\Delta \mathrm{V}_{*_{\text {min }}}(0.137)$. Die grootste afwyking vanaf eksperimentele waardes is verkry vir kompleks 1, soos ook waargeneem vir ander verwante passings van kompleks 1 se eksperimentele reduksiepotensiaal met verskeie teoretiese waardes, soos bereken deur die verskillende DFT-metodes. Afgesien van kompleks 1 , is die ander verbindings se eksperimentele reduksiepotensiale tot ' $n$ redelike mate van akkuraatheid weergee, deur die lineêre regressieformules wat verkry is vanaf $\Delta \mathrm{V}_{*_{\mathrm{Mn}}}$ and $\Delta \mathrm{V}_{*_{\mathrm{I}} \mathrm{O}}$. 


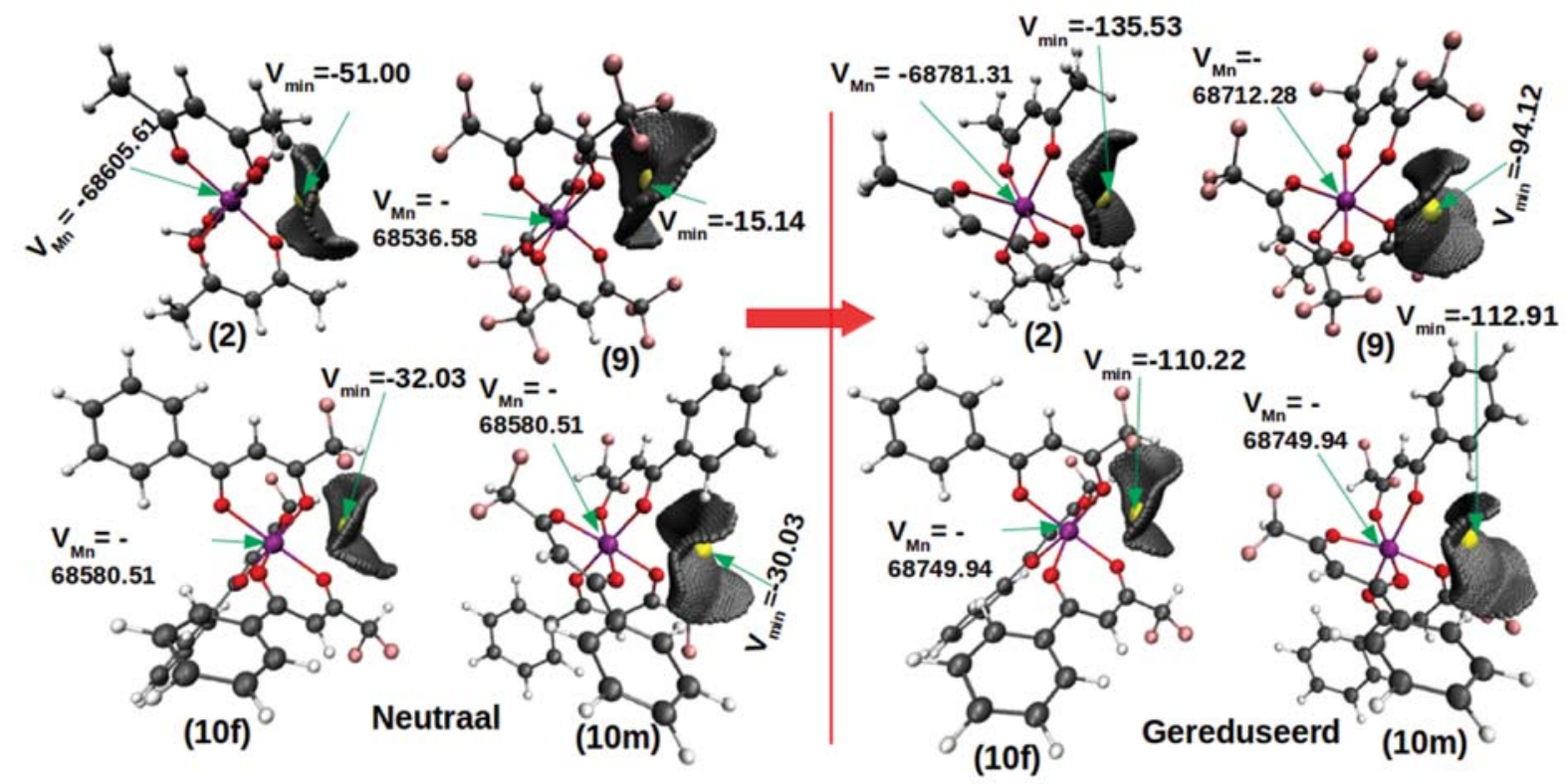

FIGUUR 5: Die MESP iso-oppervlak, met die minimum elektrostatiese punt ( $\mathrm{V}$ in $\mathrm{kcal} / \mathrm{mol}$ ) en $\mathrm{Mn}$ se atoompotensiaal ( $\mathrm{V}$ in au) vir verbinding 2 (met twee $\mathrm{CH}_{3}$-groepe per $\beta$-diketonato ligand), vir 9 (twee $\mathrm{CF}_{3}$-groepe per $\beta$-diketonato ligand), en vir albei 10 fac-en 10 mer-isomere (met een $\mathrm{CH}_{3}$ - en een $\mathrm{CF}_{3}$-groep per $\beta$-diketonato ligand), in beide hul neutrale en gereduseerde toestand. 1 a.u. $=627,51 \mathrm{kcal} / \mathrm{mol}$.

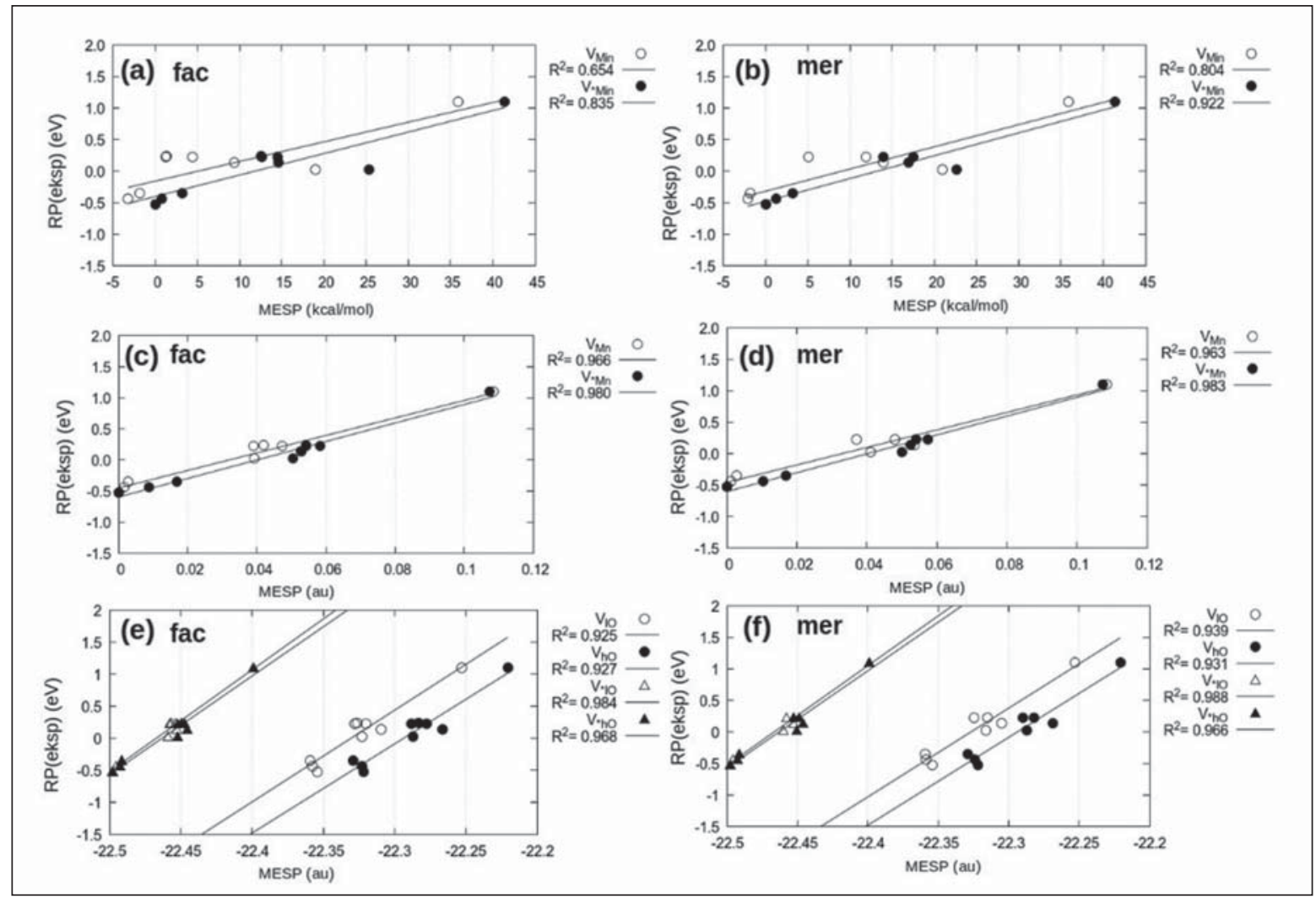

FIGUUR 6: Korrelasie van die eksperimentele reduksiepotensiaal met (a) en (b) die minimum elektrostatiese punt ( $\mathrm{V}_{\min }$ in $\mathrm{kcal} / \mathrm{mol}$ ), met (c) en (d) die atoompotensiaal van $\mathrm{Mn}\left(\mathrm{V}_{\mathrm{in}}\right.$ iu), en met (e) en (f) die atoompotensiaal van die twee O-atome ( $\mathrm{V}$ in au, waar "l" die $\mathrm{O}$ met die laagste waarde aandui, en " $\mathrm{h}$ " die $\mathrm{O}$ met die hoogste waarde aandui), vir beide die fac- ( $a$, $c$ en e) en mer-isomere (b, $d$ en f) saam met die simmetriese molekules van die neutrale kompleks asook die gereduseerde kompleks $(*)$, waar van toepassing. Alle reduksiepotensiale is in $\mathrm{V}$ vs $\mathrm{Fc} / \mathrm{Fc}^{+} .1$ a.u. $=627.51 \mathrm{kcal} / \mathrm{mol}$. 
TABEL 4: Teoretiese elektrostatiese potensiaal van die twee O-atome (O met die laagste waarde aangedui deur "I" en die hoogste waarde aangedui deur " $h$ "), bereken die neutrale komplekse asook die gereduseerde kompleks $\left({ }^{*}\right)$. Die $\mathrm{V}_{\mathrm{mn}}$ and $\mathrm{V}_{\mathrm{o}}$-waardes is in au, en $\mathrm{V}_{\text {min }}$-waardes in kcal/mol. MAD is bereken sonder kompleks 1 , wat grootliks afgewyk het van die waargenome neigings. Voorspelde reduksiepotensiaal-waardes (RP) (in $\mathrm{V} v s \mathrm{Fc} / \mathrm{Fc}^{+}$) is verkry deur lineêre regressie-passing, soos aangedui.

\begin{tabular}{|c|c|c|c|c|c|c|c|c|c|c|c|c|}
\hline & \multirow[b]{2}{*}{$\mathrm{RP}(\mathrm{eksp})$} & \multirow[b]{2}{*}{$\mathrm{V}_{\min }$} & \multirow[b]{2}{*}{$\mathrm{V}_{*_{\text {min }}}$} & \multirow[b]{2}{*}{$\mathrm{V}_{\mathrm{Mn}}$} & \multicolumn{2}{|c|}{ MESP parameter } & \multirow[b]{2}{*}{$V_{\text {ho }}$} & \multirow[b]{2}{*}{$\mathrm{V}_{* \mid \mathrm{O}}$} & \multirow[b]{2}{*}{$\mathrm{V}_{* \mathrm{hO}}$} & \multicolumn{3}{|c|}{$\begin{array}{c}\mathrm{RP}_{\text {voorspel }} \text { vanaf lineêre } \\
\text { regressie-passing } \\
\text { (met gebruik van mer + simmetries) }\end{array}$} \\
\hline & & & & & $\mathrm{V}_{{ }^{*} \mathrm{Mn}}$ & $V_{10}$ & & & & $\Delta \mathrm{V}_{*_{\text {min }}}$ & $\Delta \mathrm{V}_{{ }^{*} \mathrm{Mn}}$ & $\Delta \mathrm{V}_{* \mid \mathrm{O}}$ \\
\hline 1 & -0.964 & -45.92 & -128.36 & -109.33 & -109.59 & -22.35 & -22.32 & -22.49 & -22.49 & -0.221 & -0.357 & -0.428 \\
\hline 2 & -0.520 & -51.00 & -135.53 & -109.33 & -109.61 & -22.35 & -22.32 & -22.50 & -22.50 & -0.479 & -0.602 & -0.494 \\
\hline $3 f$ & -0.431 & -54.19 & -134.77 & -109.33 & -109.60 & -22.36 & -22.32 & -22.50 & -22.49 & -0.451 & -0.471 & -0.454 \\
\hline $3 m$ & -0.431 & -53.12 & -134.31 & -109.33 & -109.60 & -22.36 & -22.32 & -22.50 & -22.49 & -0.435 & -0.448 & -0.462 \\
\hline 4 & -0.351 & -52.87 & -132.31 & -109.33 & -109.59 & -22.36 & -22.33 & -22.49 & -22.49 & -0.363 & -0.351 & -0.390 \\
\hline $5 f$ & 0.132 & -41.63 & -120.93 & -109.28 & -109.56 & -22.31 & -22.27 & -22.45 & -22.45 & 0.047 & 0.188 & 0.213 \\
\hline $5 \mathrm{~m}$ & 0.132 & -37.06 & -118.56 & -109.28 & -109.56 & -22.31 & -22.27 & -22.45 & -22.45 & 0.132 & 0.184 & 0.219 \\
\hline $6 f$ & 0.223 & -49.75 & -122.91 & -109.29 & -109.55 & -22.33 & -22.29 & -22.46 & -22.45 & -0.024 & 0.211 & 0.140 \\
\hline $6 m$ & 0.223 & -45.94 & -121.57 & -109.30 & -109.55 & -22.32 & -22.29 & -22.46 & -22.45 & 0.024 & 0.207 & 0.142 \\
\hline $7 f$ & 0.236 & -49.64 & -122.98 & -109.29 & -109.55 & -22.33 & -22.28 & -22.46 & -22.45 & -0.027 & 0.210 & 0.157 \\
\hline $7 m$ & 0.236 & -43.12 & & -109.29 & & -22.32 & -22.29 & & & & & \\
\hline $8 f$ & 0.225 & -46.58 & -121.04 & -109.29 & -109.55 & -22.32 & -22.28 & -22.45 & -22.45 & 0.043 & 0.272 & 0.200 \\
\hline $8 m$ & 0.225 & -39.12 & -118.02 & -109.29 & -109.55 & -22.31 & -22.28 & -22.45 & -22.45 & 0.152 & 0.260 & 0.218 \\
\hline 9 & 1.095 & -15.14 & -94.12 & -109.22 & -109.50 & -22.25 & -22.22 & -22.40 & -22.40 & 1.012 & 1.006 & 1.068 \\
\hline $10 f$ & 0.030 & -32.03 & -110.22 & -109.29 & -109.56 & -22.32 & -22.29 & -22.46 & -22.45 & 0.432 & 0.155 & 0.118 \\
\hline $10 \mathrm{~m}$ & 0.030 & -30.03 & -112.91 & -109.29 & -109.56 & -22.32 & -22.29 & -22.46 & -22.45 & 0.335 & 0.148 & 0.100 \\
\hline MAD & & & & & & & & & & 0.137 & 0.051 & 0.053 \\
\hline
\end{tabular}

\section{Gevolgtrekking}

'n Betroubare teoretiese metode vir die berekening van teoretiese redokspotensiale van die $\mathrm{Mn}^{\mathrm{III}} / \mathrm{Mn}^{\mathrm{II}}$ - en $\mathrm{Mn}^{\mathrm{III}} / \mathrm{Mn}^{\mathrm{IV}}$-redokspare van verskeie tris( $\beta$-diketonato) mangaan(III) komplekse, is in hierdie studie aangebied. Hierdeur word die voorspelling van onbekende $[\mathrm{Mn}(\beta-$ diketonato) $)_{3}$-komplekse se redokspotensiaal moontlik gemaak sonder vooraf chemiese sintesereaksies, en daarmee saam ook hul aktiwiteit en geskiktheid vir 'n spesifieke toepassing. Hierdie metode kom boonop handig te pas by $\left[\mathrm{Mn}(\beta \text {-diketonato })_{3}\right]$ komplekse, om $\mathrm{Mn}^{\mathrm{III}} / \mathrm{Mn}^{\mathrm{IV}}$-redokspare se redokspotensiaal wat nie elektrochemies eksperimenteel gemeet kan word nie, wel teoreties te kan bepaal.

Hierdie berekeningsmetode het die meeste van die eksperimentele reduksiepotensiale tot 'n beduidende vlak van akkuraatheid weergee in die teorie, behalwe vir kompleks 1 wat aansienlik van die eksperimentele waarde afgewyk het, waarskynlik omdat laasgenoemde waardes nie onder dieselfde eksperimentele toestande verkry is as komplekse 2 - 10 nie: kompleks 1 se sikliese voltammogramme is in dichloormetaan gemeet, terwyl die eksperimentele reduksiepotensiale van komplekse 2 - 10, asook die berekende reduksiepotensiale van al tien komplekse, in asetonitriel verkry is. Vanuit die drie DFT metodes het metode M06 (MAD=0.102 eV) die eksperimentele reduksiepotensiaal beter weergegee as beide metodes M062X (MAD $=0.408)$ wat die waardes oorskat het en B3LYP $($ MAD $=0.317)$ wat die waardes onderskat het. Hierdie drie DFT-metodes het die eksperimentele neiging tot ' $\mathrm{n}$ hoë vlak van akkuraatheid weergee. $\mathrm{R}^{2}$ waardes van 0.970, 0.973 and 0.961 is onderskeidelik vir M06, M062X en B3LYP verkry deur gebruik te maak van die eerste termodinamiese siklus (Figuur 2), wat die kleinste afwyking van eksperimentele waardes gee. Die mer-isomere se energie het ' $n$ relatief hoër stabiliteit getoon as die fac-isomere vir onsimmetriese komplekse 3, 5, 6, 7 en 8 , terwyl die fac-isomeer op sy beurt stabieler was vir kompleks 10. Hierdie neiging is ook weerspieël in die teoretiese reduksiepotensiale, waar die berekende waarde vir die fac-isomeer van kompleks 10 groter was as vir die mer-isomeer; presies omgekeerd as in komplekse 3 en 8 . Wanneer die sterkte van die elektrondonorgroep op die $\beta$-diketonato ligande verhoog is, het dit ' $n$ meer negatiewe reduksiepotensiaal vir die $\left[\mathrm{Mn}(\beta \text {-diketonato) })_{3}\right]$-komplekse veroorsaak, terwyl meer elektrononttrekkende groepe op die ligande 'n meer positiewe reduksiepotensiaal gelewer het. Asimmetriese kombinasie van beide ' $n$ elektrononttrekkende- en elektrondonerende groep het gelei tot 'n laer reduksiepotensiaal en het sodoende die verbinding se reduksie verbeter. Beter reduksie van die komplekse het gelei tot ' $n$ afname in entropie en Gibbs vrye-energie van sowel die gasfase as die oplosmiddelfase, wat die hoogste waarde vir die totale Gibbs vrye-energie vir die reaksie gegee het $\left(\Delta \mathrm{G}_{\mathrm{rksie}}\right)$. Hierdie termodinamiese effek was meer prominent in verbindings met sterk elektrononttrekkende groepe, soos kompleks 9 met twee $\mathrm{CF}_{3}$-groepe per $\beta$-diketonato-ligand. Berekeningschemie het ook die eksperimentele oksidasiepotensiale wat beskikbaar was in die literatuur weergee, vir simmetriese komplekse 2, 3, 4 en 10, maar het 'n beduidende afwyking getoon vir kompleks 1 , soos ook waargeneem is vir sy reduksiepotensiaal. Die resultate het ook insig gegee in die oksidasiepotensiale van komplekse 5, 6, 7, 8 en 9 wat nie eksperimenteel meetbaar was nie, aangesien hulle waardes buite die eksperimentele oplosmiddelvenster val. Daar was ' $\mathrm{n}$ beduidende korrelasie, wat toon dat komplekse met ' $n$ hoër reduksiepotensiaal, soos kompleks 9, ook 'n hoër oksidasiepotensiaal het, met gevolglik hoër ionisasiepotensiaal en ooreenstemmende hoër elektronaffiniteit. 
Die MESP-minima is gewoonlik aangetref in die area tussen twee koördineerder-suurstofatome van verskillende $\beta$-diketonato-ligande. Vir mer-isomere was die MESP-minima by voorkeur in die omgewing van die elektrononttrekkende substituent. Die MESP-parameter van die komplekse se gereduseerde toestand het die beste korrelasie getoon en waardes vir eksperimentele reduksie die beste voorspel. Die MESP-waarde van òf die Mn-atoom òf enige van die koördineerder-suurstofatome met die laagste elektrostatiese potensiaalwaarde, het die akkuraatste voorspelling gegee vir eksperimentele reduksiepotensiaal.

\section{Outeurbydraes}

JC en AA het die projek konseptualiseer en beplan; AA het die berekeningschemie gedoen en die artikel geskryf, met redigering wat deur JC gedoen is.

\section{Erkenning}

Die outeurs wil graag erkenning gee aan die Universiteit van die Vrystaat en die Nasionale Navorsingsraad van Suid-Afrika vir finansiële steun (Beurs-nommers: 109673, 113327 en 96111). Die CHPC van Suid-Afrika, die Noorweegse Supercomputer-Program (UNINETT Sigma2, Beurs-nommers. NN9684K) en die UV se UV se hoëverwerkings-rekenaarfasiliteit, word almal erken vir berekeningstyd.

\section{Ondersteunende Materiaal}

Bykomende grafieke en tabelle word in die Ondersteunende Materiaal voorsien.

\section{Verwysings}

Adeniyi AA, Conradie J. 2019. Computational insight into the contribution of para-substituents on the reduction potential, proton affinity, and electronic properties of nitrobenzene compounds. J Mol Model 25, 78. https://doi. properties of nitrobenzene compon/s00894-019-3946-2

Adeniyi AA, Conradie J. 2018. Influence of substituents on the reduction potential and pKa values of $\beta$-diketones tautomers: A theoretical study. Electrochim Acta https://doi.org/https://doi.org/10.1016/j.electacta.2018.12.030

Anjali BA, Sayyed FB, Suresh CH. 2016. Correlation and prediction of redox potentials of hydrogen evolution mononuclear cobalt catalysts via molecular electrostatic potential: A DFT Study. J Phys Chem A 120, 1112-1119. https:// doi.org/10.1021/acs.jpca.5b11543

Anjali BA, Suresh CH. 2018. Electronic effect of ligands vs. reduction potentials of Fischer carbene complexes of chromium : a molecular electrostatic potential analysis. New J Chem 42, 18217-18224. https://doi.org/10.1039/C8NJ04184A

Bag N, Lahiri GK, Bhattacharya S, Falvello LR, Chakravorty A. 1988. Ruthenium phenolates. Chemistry of a family of RullIO6 tris chelates. Inorg Chem 27, 4396-4402. https://doi.org/10.1021/ic00297a014

Bouwman E, Van Gorkum R. 2007. A study of new manganese complexes as potential driers for alkyd paints. J Coatings Technol Res 4, 491-503. https:// doi.org/10.1007/s11998-007-9041-0

Bryant JR, Taves JE, Mayer JM. 2002. Oxidations of Hydrocarbons by Manganese(III) Tris(hexafl uoroacetylacetonate). Inorg Chem 41, 2769-2776. https://doi. org/10.1021/ic025541z

Carli S, Benazzi E, Casarin L, Bernardi T, Bertolasi V, Argazzi R, Caramori S, Bignozzi CA. 2016. On the stability of manganese tris( $\beta$-diketonate) complexes as redox mediators in DSSCs. Phys Chem Chem Phys 18, 5949-5956. https://doi. org/10.1039/c5cp05524e

Chattopadhyay S, Bag N, Basu P, Lahiri GK, Chakravorty A. 1990. Oxo transfer and metal oxidation in the reaction of $[\mathrm{Ru}(\mathrm{PPh} 3) 3 \mathrm{Cl} 2]$ with m-chloroperbenzoic acid: structure of [Ru(PPh3)2(m-ClC6H4CO2)Cl2]. J Chem Soc Dalt Trans 33893392. https://doi.org/10.1039/DT9900003389
Cornioley-Deuschel C, Von Zelewsky A. 1987. Complexes of platinum(II) and palladium(II) with the $2,2^{\prime}$-biphenyldiyl dianion as a .sigma.-bonded chelate ligand. Inorg Chem 26, 3354-3358. https://doi.org/10.1021/ic00267a028

Dewar MJS, Nakaya T. 1968. Oxidative coupling of phenols. J Am Chem Soc 90, 7134-7135. https://doi.org/10.1021/ja01027a051

Eskelinen E, Da Costa P, Haukka M. 2005. The synthesis and electrochemical behavior of ruthenium (III) bipyridine complexes: [Ru(dcbpy) Cl4]- (dcbpy=4,4' dicarboxylic acid-2,2'-bipyridine) and [Ru(bp) $\mathrm{Cl} 3 \mathrm{~L}]\left(\mathrm{L}=\mathrm{CH} 3 \mathrm{OH}_{2} \mathrm{PPh} 3,4,4^{\prime}\right.$ bpy, CH3CN). J Electroanal Chem 579, 257-265. https://doi.org/https://doi. org/10.1016/j.jelechem.2005.02.014

Freitag R, Conradie J. 2015. Electrochemical and Computational Chemistry Study of $\mathrm{Mn}$ ( $\beta$-diketonato) 3 complexes. Electrochim Acta 158, 418-426. https://doi. org/https://doi.org/10.1016/j.electacta.2015.01.147

Frisch MJ, Trucks GW, Schlegel HB, Scuseria GE, Robb MA, Cheeseman JR, et al. 2009. Gaussian 09.

Fu Y, Liu L, Yu H, Wang Y, Guo Q. 2005. Quantum-chemical predictions of absolute standard redox potentials of diverse organmeanic molecules and free radicals in acetonitrile. J Am Chem Soc 127, 7227-7234. https://doi.org/10.1021/ ja0421856

Gadre SR, Shirsat RN. 2001. Electrostatics of atoms and molecules. Universities Press, India.

Gritzner G, Murauer H, Gutmann V. 1979. Solvent and salt effects on the redox behaviour of trisacetylacetonatomanganese(III). J Electroanal Chem 101 185-200.

Holligan BM, Jeffery JC, Norgett MK, Schatz E, Ward MD. 1992. The coordination chemistry of mixed pyridine-phenol ligands; spectroscopic and redox properties of mononuclear ruthenium complexes with (pyridine)6(phenolate) donor sets ( $x=1$ or 2). J Chem Soc Dalt Trans 3345-3351. https:// doi.org/10.1039/DT9920003345

Humphrey W, Dalke A, Schulten K. 1996. VMD: visual molecular dynamics. J Mo Graph 14, 27-28,33-38.

Kenvin JC, White MG, Mitchell MB. 1991. Preparation and characterization of supported mononuclear metal complexes as model catalysts. Langmuir 7 , 1198-1205. https://doi.org/10.1021/la00054a030

Khusnutdinov RI, Shchadneva NA, Baiguzina AR, Lavrentieva YY, Dzhemilev UM 2002. Generation of alkyl hypochlorites in oxidation of alcohols with carbon tetrachloride catalyzed by vanadium and manganese compounds. Russ Chem Bull 51, 2074-2079. https://doi.org/10.1023/A:1021668011691

Lahiri GK, Bhattacharya S, Ghosh BK, Chakravorty A. 1987. Ruthenium and osmium complexes of $\mathrm{N}, \mathrm{O}$ chelators: syntheses, oxidation levels, and distortion parameters. Inorg Chem 26, 4324-4331. https://doi.org/10.1021/ ic00273a010

Lu T, Chen F. 2012a. Multiwfn: a multifunctional wavefunction analyzer. J Comput Chem 33, 580-592. https://doi.org/10.1002/jcc.22885

Lu T, Chen F. 2012b. Quantitative analysis of molecular surface based on improved Marching Tetrahedra algorithm. J Mol Graph Model 38, 314-323. https://doi. org/https://doi.org/10.1016/j.jmgm.2012.07.004

Magnus P, Payne AH, Waring MJ, Scott DA, Lynch V. 2000. Conversion of $\alpha, \beta$ unsaturated ketones into $\alpha$-hydroxy ketones using an $\mathrm{Mn}(\mathrm{III})$ catalyst, phenylsilane and dioxygen: acceleration of conjugate hydride reduction by dioxygen. Tetrahedron Lett 41, 9725-9730. https://doi.org/https://doi org/10.1016/S0040-4039(00)01727-5

Marenich AV, Cramer CJ, Truhlar DG. 2009. Universal solvation model based on solute electron density and on a continuum model of the solvent defined by the bulk dielectric constant and atomic surface tensions. J Phys Chem B 113, 6378-6396.

Marenich AV, Ho J, Coote ML, Cramer CI, Truhlar DG. 2014. Computational electrochemistry: prediction of liquid-phase reduction potentialst. Phys Chem electrochemistry: prediction of liquid-phase reduction potentialst.
Chem Phys 16, 15068-15106. https://doi.org/10.1039/c4cp01572j

Mohan N, Suresh CH, Kumar A, Gadre SR. 2013. Molecular electrostatics for probing lone pair-p interactions. Phys Chem Chem Phys 15, 18401-18409. https://doi. org/10.1039/c3cp53379d

Namazian M, Lin CY, Coote ML. 2010. Benchmark calculations of absolute reduction potential of Ferricinium/Ferrocene couple in nonaqueous solutions. J Chem Theory Comput 6, 2721-2725. https://doi.org/10.1021/ct1003252

Perera IR, Gupta A, Xiang W, Daeneke T, Bach U, Evans RA, et al. 2014. Introducing manganese complexes as redox mediators for dye-sensitized solar cells. Phys Chem Chem Phys 16, 12021-12028. https://doi.org/10.1039/C3CP54894E

Politzer P, Murray JS. 2002. The fundamental nature and role of the electrostatic potential in atoms and molecules. Theor Chem Acc 108, 134-142. https://doi. org/10.1007/s00214-002-0363-9

Politzer P, Murray JS, Peralta-Inga Z. 2001. Molecular surface electrostatic potentials in relation to noncovalent interactions in biological systems. Int $J$ Quantum Chem 85, 676-684. https://doi.org/10.1002/qua.1706

R-Core-Team2018. The R Core Team: A language and environment for statistical computing. 
Remya GS, Suresh CH. 2018. Assessment of the electron donor properties of substituted phenanthroline ligands in molybdenum carbonyl complexes using molecular electrostatic potentials. New J Chem 42, 3602-3608. https://doi. org/10.1039/C7NJ04592A

Remya K, Suresh CH. 2016. Carbon rings: a DFT study on geometry, aromaticity, intermolecular carbon-carbon interactions and stability. $R$ Society Chem Adv 6, 44261-44271. https://doi.org/10.1039/c6ra06833b

Rillema DP, Jones DS. 1979. Structure of tris(2,2'-bipyridyl)ruthenium(II) hexafluorophosphate, [Ru(bipy)3][PF6]2; X-ray crystallographic determination. J Chem Soc Chem Commun 849-851. https://doi.org/10.1039/C39790000849

Skyner RE, Mcdonagh JL, Groom CR, Van Mourik T. 2015. A review of methods for the calculation of solution free energies and the modelling of systems in solution. Phys Chem Chem Phys 17, 6174-6191. https://doi.org/10.1039/ C5CP00288E

Sleightholme AES, Shinkle AA, Liu Q, Li Y, Monroe CW, Thompson LT. 2011. Nonaqueous manganese acetylacetonate electrolyte for redox flow batteries. Power Sources 196, 5742-5745. https://doi.org/https://doi.org/10.1016/j. jpowsour.2011.02.020

Sodhi RK, Paul S. 2011. Nanosized Mn(acac)3 anchored on amino functionalized silica for the selective oxidative synthesis of 2-arylbenzimidazoles, 2 -arylbenzothiazoles and aerobic oxidation of benzoins in water. Catal Letters 141, 608-615. https://doi.org/10.1007/s10562-010-0540-8
Sudo A, Hirayama S, Endo T. 2010. Highly efficient catalysts-acetylacetonato complexes of transition metals in the 4th period for ring-opening polymerization of 1,3-benzoxazine. J Polym Sci Part A Polym Chem 48, 479484. https://doi.org/10.1002/pola.23810

Van Gorkum R, Bouwman E, Reedijk J. 2004. Fast autoxidation of ethyl linoleate catalyzed by $[\mathrm{Mn}(\mathrm{acac}) 3]$ and bipyridine: A possible drying catalyst for alkyd paints. Inorg Chem 43, 2456-2458. https://doi.org/10.1021/ic0354217

Wang Y-F, Chiba S. 2009. Mn(III)-mediated reactions of cyclopropanols with viny azides: synthesis of pyridine and 2-Azabicyclo[3.3.1]non-2-en-1-ol derivatives. J Am Chem Soc 131, 12570-12572. https://doi.org/10.1021/ja905110c

Yang K, Bott SG, Richmond MG. 1993. Bidentate ligand substitution in PhCCo3(CO)9. Synthesis, molecular structure, and redox reactivity of $\mathrm{PhCCo3}(\mathrm{CO}) 7$ (cisPh2PCHкCHPPh2. J. Organomet Chem 454, 273-280. https://doi.org/https:// doi.org/10.1016/0022-328X(93)83251-P

Zhao Y, Truhlar DG. 2006. A new local density functional for main-group thermochemistry, transition metal bonding, thermochemical kinetics, and noncovalent interactions. J Chem

Phys 125, 194101. https://doi.org/10.1063/1.2370993 


\section{Ondersteunende Materiaal}

\section{Inhoud}

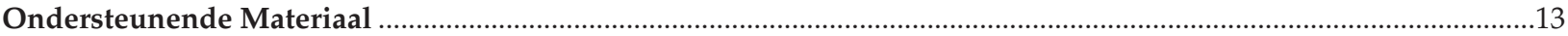

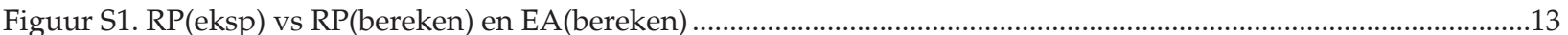

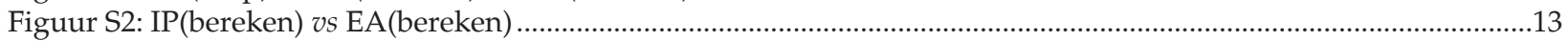

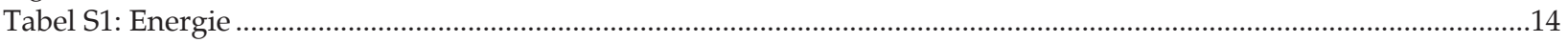

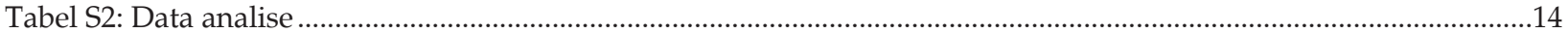

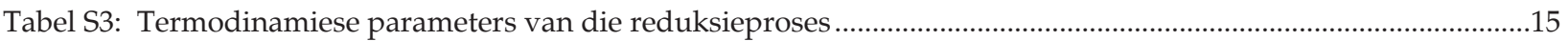

FIGUUR S1: RP(eksp) vs RP(bereken) en EA(bereken)

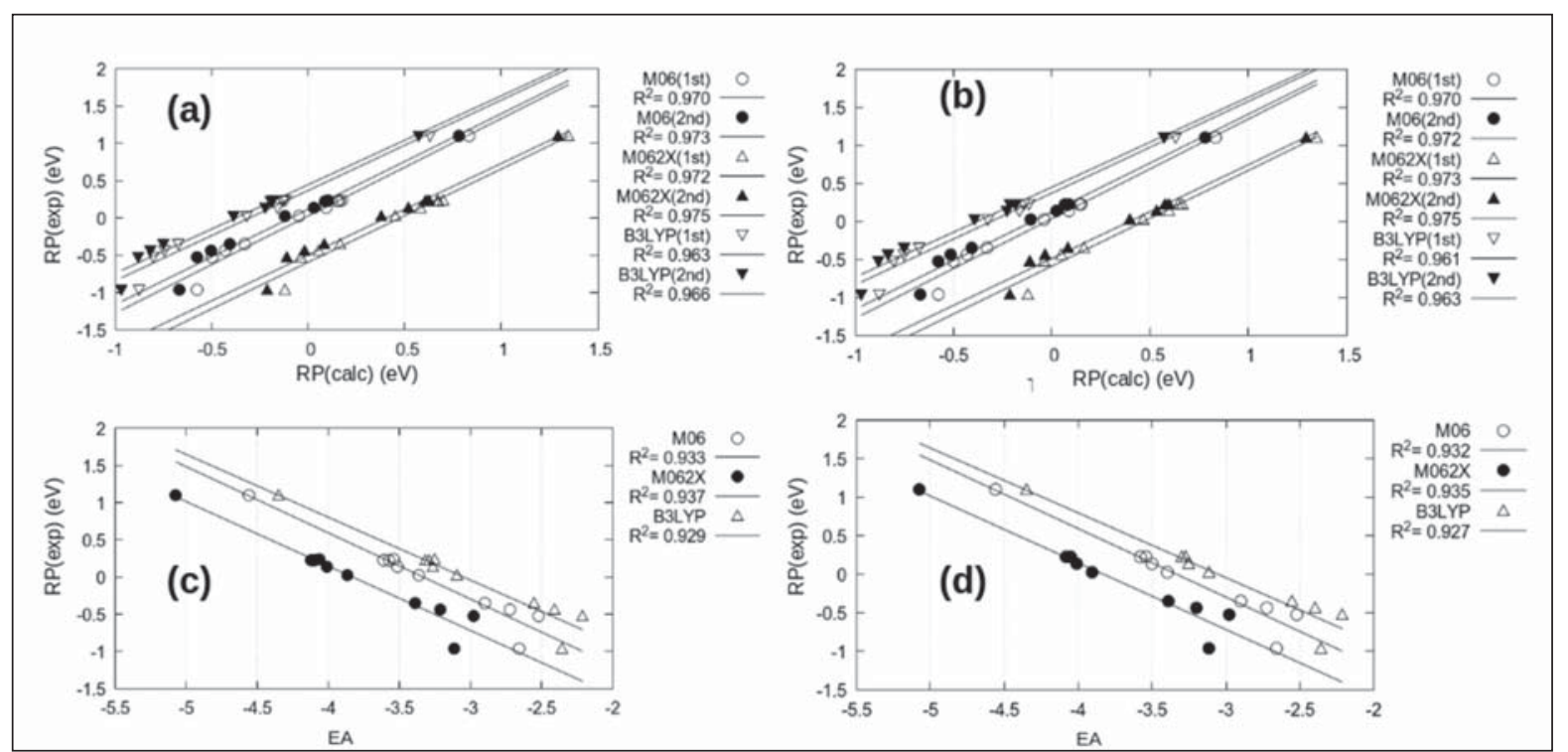

FIGUUR S1. Die korrelasie van die eksperimentele reduksiepotensiaal (RP(exp)) met die berekende (a) reduksiepotensiaal, $\mathrm{RP}$ (calc), van sowel die simmetries gesubstitueerde komplekse 1, 2, 4 en 9, asook die fac-isomere van die onsimmetriese komplekse 3, 5, 6, 7, 8 en 10, (b) reduksiepotensiaal van sowel die simmetries gesubstitueerde komplekse 1, 2, 4 en 9, asook die mer-isomere van die onsimmetriese komplekse 3, 5, 6, 7, 8 en 10, (c) elektron-affiniteit van sowel die simmetries gesubstitueerde komplekse 1, 2, 4 en 9, asook die fac-isomere van die onsimmetriese komplekse 3, 5, 6, 7, 8 en 10, en (d) elektron-affiniteit van sowel die simmetries gesubstitueerde komplekse 1, 2, 4 en 9, asook die mer-isomere van die onsimmetriese komplekse 3, 5, 6, 7,8 en 10. Alle reduksiepotensiale is in $\mathrm{V}$ vs $\mathrm{Fc} / \mathrm{Fc}^{+}$.

FIGUUR S2: IP(bereken) vs EA(bereken)

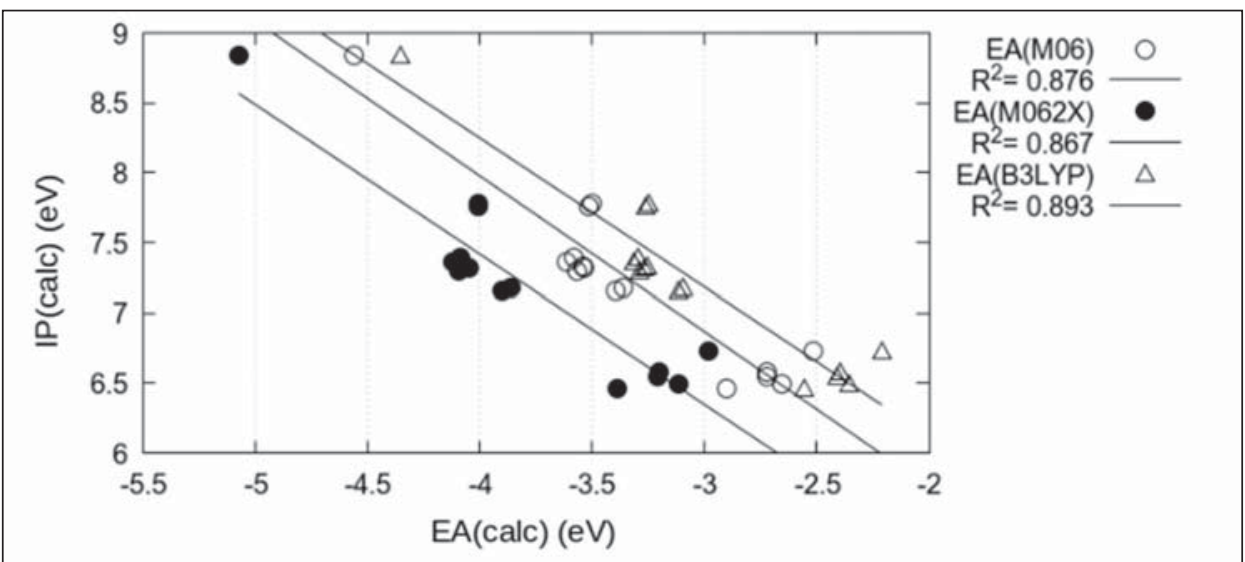

FIGUUR S2: Die korrelasie van die berekende ionisasiepotensiaal, IP(calc), met behulp van M06 met die berekende elektronaffiniteite, EA(calc), bereken deur gebruik te maak van M06, M062X en B3LYP. 
TABEL S1: Energie

\begin{tabular}{cccc}
\hline & $E(B 3 L Y P)$ & $E(M 06)$ & $E(M 062 X)$ \\
\hline 1 & -78762.70 & -78740.45 & -78753.60 \\
2 & -59505.27 & -59494.23 & -59500.97 \\
$3 f$ & -75158.82 & -75138.76 & -75151.95 \\
$3 m$ & -75158.83 & -75138.77 & -75151.95 \\
4 & -90812.37 & -90783.28 & -90802.92 \\
$5 f$ & -83810.65 & -83800.44 & -83807.54 \\
$5 m$ & -83810.68 & -83800.46 & -83807.55 \\
$6 f$ & -125648.83 & -125633.61 & -125644.75 \\
$6 m$ & -125648.86 & -125633.65 & -125644.80 \\
$7 f$ & -99282.89 & -99266.99 & -99278.54 \\
$7 m$ & -99282.93 & -99267.02 & -99278.56 \\
$8 f$ & -99464.25 & -99444.99 & -99458.53 \\
$8 m$ & -99464.29 & -99445.04 & -99458.56 \\
9 & -108115.54 & -108106.17 & -108113.62 \\
$10 f$ & -91361.76 & -91342.00 & -91355.49 \\
$10 m$ & -91361.75 & -91341.98 & -91355.46 \\
\hline
\end{tabular}

TABEL S1. Die energie (eV) van die neutrale toestand van die komplekse

TABEL S2. Die parameters van die regressievergelyking Eksp $(\mathbf{R P})=\mathbf{b} \mathbf{0}+\mathbf{b} \mathbf{1 X} \mathbf{1}$ wat die vlak van korrelasie toon van die eksperimentele reduksiepotensiaal (Eksp (RP)) met (a, b) die berekende reduksiepotensiaal met behulp van M06, M062X en B3LYP DFT funksionaal, (c, d). elektronaffiniteit met behulp van M06, M062X en B3LYP DFT funksionaal, $(e, f)$ die verandering in MESP minimum $\left(\Delta \mathrm{V}_{\min }\right)$, en $(g$, h) elektrostatiese potensiaal van $\mathrm{Mn}$ atoom $\left(\Delta \mathrm{V}_{\mathrm{Mn}}\right)$, (i, j) die laagste (begin met l) en die hoogste (begin met $h$ ) elektrostatiese potensiaal van die koördinerende O-atome. Die korrelasie is met die simmetries gesubstitueerde molekules en óf die fac- of mer-isomere soos aangedui.

TABEL S2: Data analise

\begin{tabular}{|c|c|c|c|c|c|c|c|}
\hline $\mathbf{X 1}$ & R2 & b0 & b1 & RSE & t-waarde & $\operatorname{Pr}(>|t|)$ & F-statistiek \\
\hline \multicolumn{8}{|c|}{ (a). Berekende reduksiepotensiaal (RP(bereken)) met M06, M062X en B3LYP vir die simmetriese molekules en fac isomere } \\
\hline $\mathrm{E}(\mathrm{M} 06-1 \mathrm{e}) \mathrm{fac}$ & 0.970 & 0.030 & 1.304 & 0.104 & 16.085 & $2.24 \mathrm{E}-07$ & 258.70 \\
\hline E(M06-2de) fac & 0.973 & 0.120 & 1.277 & 0.099 & 16.943 & $1.49 \mathrm{E}-07$ & 287.00 \\
\hline $\mathrm{E}(\mathrm{M} 062 \mathrm{X}-1 \mathrm{e}) \mathrm{fac}$ & 0.973 & -0.591 & 1.250 & 0.099 & 16.810 & $1.59 \mathrm{E}-07$ & 282.50 \\
\hline $\mathrm{E}(\mathrm{M} 062 \mathrm{X}-2 \mathrm{de}) \mathrm{fac}$ & 0.975 & -0.494 & 1.226 & 0.094 & 17.750 & $1.04 \mathrm{E}-07$ & 315.10 \\
\hline E(B3LYP-1e) fac & 0.963 & 0.372 & 1.210 & 0.116 & 14.344 & $5.45 \mathrm{E}-07$ & 205.70 \\
\hline E(B3LYP-2de) fac & 0.966 & 0.449 & 1.188 & 0.111 & 14.990 & 3.87E-07 & 224.70 \\
\hline \multicolumn{8}{|c|}{ (b). Berekende reduksiepotensiaal (RP(bereken)) met M06, M062X en B3LYP vir die simmetriese molekules en mer isomere } \\
\hline $\mathrm{E}(\mathrm{M} 06-1 \mathrm{e}) \mathrm{mer}$ & 0.970 & 0.035 & 1.310 & 0.110 & 15.009 & 1.4E-06 & 225.30 \\
\hline $\mathrm{E}(\mathrm{M} 06-2 \mathrm{de}) \mathrm{mer}$ & 0.972 & 0.126 & 1.282 & 0.105 & 15.640 & 1.06E-06 & 244.60 \\
\hline $\mathrm{E}(\mathrm{M} 062 \mathrm{X}-1 \mathrm{e}) \mathrm{mer}$ & 0.973 & -0.589 & 1.259 & 0.104 & 15.850 & $9.63 \mathrm{E}-07$ & 251.30 \\
\hline $\mathrm{E}(\mathrm{M} 062 \mathrm{X}-2 \mathrm{de}) \mathrm{mer}$ & 0.975 & -0.489 & 1.233 & 0.100 & 16.500 & 7.33E-07 & 272.20 \\
\hline E(B3LYP-1e) mer & 0.961 & 0.372 & 1.207 & 0.125 & 13.067 & $3.58 \mathrm{E}-06$ & 170.70 \\
\hline E(B3LYP-2de) mer & 0.963 & 0.449 & 1.183 & 0.122 & 13.493 & $2.88 \mathrm{E}-06$ & 182.00 \\
\hline \multicolumn{8}{|c|}{ (c). Berekende elektronaffiniteit (EA) met M06, M062X en B3LYP vir die simmetriese molekules en fac isomere } \\
\hline $\mathrm{EA}(\mathrm{M} 06) \mathrm{fac}$ & 0.933 & -2.967 & -0.890 & 0.155 & -10.580 & 5.56E-06 & 112.00 \\
\hline $\mathrm{EA}(\mathrm{M} 062 \mathrm{X}) \mathrm{fac}$ & 0.938 & -3.317 & -0.866 & 0.150 & -10.950 & 4.29E-06 & 119.90 \\
\hline $\mathrm{EA}(\mathrm{B} 3 \mathrm{LY} \mathrm{P}) \mathrm{fac}$ & 0.929 & -2.576 & -0.845 & 0.160 & -10.230 & 7.15E-06 & 104.70 \\
\hline \multicolumn{8}{|c|}{ (d). Berekende elektronaffiniteite (EA) met M06, M062X en B3LYP vir die simmetriese molekules en mer isomere } \\
\hline $\mathrm{EA}(\mathrm{M} 06) \mathrm{mer}$ & 0.932 & -2.967 & -0.890 & 0.165 & -9.762 & $2.51 \mathrm{E}-05$ & 95.29 \\
\hline $\mathrm{EA}(\mathrm{M} 062 \mathrm{X}) \mathrm{mer}$ & 0.935 & -3.318 & -0.867 & 0.161 & -10.030 & $2.11 \mathrm{E}-05$ & 100.50 \\
\hline EA(B3LYP) mer & 0.928 & -2.568 & -0.841 & 0.170 & -9.460 & $3.08 \mathrm{E}-05$ & 89.50 \\
\hline \multicolumn{8}{|c|}{$\begin{array}{l}\text { (e). Verandering in MESP minima }\left(\Delta \mathrm{V}_{\min }\right) \text { gebruik simmetriese molekules en die fac-isomere van die neutrale molekule en gereduseerde molekule }\left({ }^{*}\right) \text { waar var } \\
\text { toepassing }\end{array}$} \\
\hline$\Delta \mathrm{V}_{\min }(f a c)$ & 0.654 & -0.158 & 0.031 & 0.307 & 3.634 & 8.36E-03 & 13.20 \\
\hline$\Delta^{*} \mathrm{~V}_{\min }(f a c)$ & 0.835 & -0.402 & 0.034 & 0.212 & 5.955 & 5.67E-04 & 35.46 \\
\hline \multicolumn{8}{|c|}{$\begin{array}{l}\left.\text { (f). Verandering in MESP minima }\left(\Delta \mathrm{V}_{\min }\right) \text { gebruik simmetriese molekules en die } m e r \text {-isomere van die neutrale molekule en gereduseerde molekule }{ }^{*}\right) \text { waar va } \\
\text { toepassing }\end{array}$} \\
\hline$\Delta \mathrm{V}_{\min }(m e r)$ & 0.804 & -0.318 & 0.035 & 0.247 & 4.967 & $2.53 \mathrm{E}-03$ & 24.67 \\
\hline$\Delta * \mathrm{~V}_{\min }(m e r)$ & 0.922 & -0.479 & 0.036 & 0.157 & 8.399 & $1.55 \mathrm{E}-04$ & 70.54 \\
\hline \multicolumn{8}{|c|}{$\begin{array}{l}\text { (g). Verandering in elektrostatiese potensiaal van } \mathrm{Mn}\left(\Delta \mathrm{V}_{\mathrm{Mn}}\right) \text { gebruik simmetriese molekules en die fac-isomere van die neutrale molekule en gereduseerde } \\
\text { molekule }\left({ }^{*}\right) \text { waar van toepassing }\end{array}$} \\
\hline$\Delta \mathrm{V}_{\mathrm{Mn}}(f a c)$ & 0.966 & -0.450 & 14.074 & 0.097 & 14.052 & 2.19E-06 & 197.50 \\
\hline$\Delta * \mathrm{~V}_{\mathrm{Mn}}(f a c)$ & 0.980 & -0.594 & 14.873 & 0.073 & 18.620 & $3.20 \mathrm{E}-07$ & 346.70 \\
\hline \multicolumn{8}{|c|}{$\begin{array}{l}\text { (h). Verandering in elektrostatiese potensiaal van } \mathrm{Mn}\left(\Delta \mathrm{V}_{\mathrm{Mn}}\right) \text { gebruik simmetriese molekules en die mer-isomere van die neutrale molekule en gereduseerde } \\
\text { molekule }\left({ }^{*}\right) \text { waar van toepassing) }\end{array}$} \\
\hline$\Delta \mathrm{V}_{\mathrm{Mn}}($ mer $)$ & 0.963 & -0.457 & 13.911 & 0.108 & 12.440 & $1.65 \mathrm{E}-05$ & 154.70 \\
\hline$\Delta * \mathrm{~V}_{\mathrm{Mn}}(m e r)$ & 0.983 & -0.602 & 14.990 & 0.074 & 18.360 & $1.68 \mathrm{E}-06$ & 337.10 \\
\hline \multicolumn{8}{|c|}{$\begin{array}{l}\text { (i). Verandering in elektrostatiese potensiaal van twee } \mathrm{O} \text { atome (die met die laagste waarde (begin met } \mathrm{l}) \text { en die hoogste waarde (begin met } \mathrm{h}) \text { ) gebruik } \\
\text { simmetriese molekules en die fac-isomere van die neutrale molekule en gereduseerde molekule }\left({ }^{*}\right) \text { waar van toepassing }\end{array}$} \\
\hline$\Delta_{\text {Ivo }}(f a c)$ & 0.925 & -0.341 & 14.322 & 0.143 & 9.299 & $3.45 \mathrm{E}-05$ & 86.47 \\
\hline$\Delta_{\text {hvo }}(f a c)$ & 0.927 & -0.389 & 13.921 & 0.141 & 9.427 & $3.15 \mathrm{E}-05$ & 88.88 \\
\hline$\Delta_{* \mid \mathrm{V} O}(f a c)$ & 0.984 & -0.489 & 15.892 & 0.066 & 20.700 & $1.54 \mathrm{E}-07$ & 428.60 \\
\hline$\Delta_{* \mathrm{hVo}}(f a c)$ & 0.968 & -0.532 & 15.379 & 0.093 & 14.540 & $1.73 \mathrm{E}-06$ & 211.50 \\
\hline
\end{tabular}


TABEL S2: Data analise (vervolg)

\begin{tabular}{|c|c|c|c|c|c|c|c|}
\hline $\mathrm{x} 1$ & $\mathbf{R} 2$ & b0 & b1 & RSE & t-waarde & $\operatorname{Pr}(>|t|)$ & F-statistiek \\
\hline \multicolumn{8}{|c|}{$\begin{array}{l}\text { (j). Verandering in elektrostatiese potensiaal van twee } \mathrm{O} \text { atome (die met die laagste waarde (begin met l) en die hoogste waarde (begin met } \mathrm{h}) \text { ) gebruik } \\
\text { simmetriese molekules en die mer-isomere van die neutrale molekule en gereduseerde molekule }\left({ }^{*}\right) \text { waar van toepassing }\end{array}$} \\
\hline$\Delta_{\mathrm{Ivo}}(\mathrm{mer})$ & 0.939 & -0.387 & 14.049 & 0.138 & 9.642 & 7.13E-05 & 92.96 \\
\hline$\Delta_{\mathrm{hVo}}(\mathrm{mer})$ & 0.931 & -0.385 & 13.922 & 0.147 & 9.012 & $1.05 \mathrm{E}-04$ & 81.21 \\
\hline$\Delta_{* \mid \mathrm{VO}}(\mathrm{mer})$ & 0.988 & -0.494 & 15.781 & 0.062 & 22.060 & 5.67E-07 & 486.60 \\
\hline$\Delta_{* \text { *hVo }}(m e r)$ & 0.966 & -0.532 & 15.379 & 0.104 & 13.011 & $1.27 \mathrm{E}-05$ & 169.30 \\
\hline
\end{tabular}

TABEL S3. Die berekende waardes van die verandering in entropie $(\Delta \mathrm{S})$, gasfase vrye energie $(\Delta \mathrm{Ggas})$, oplossings energie $\left(\Delta \Delta \mathrm{G}_{\mathrm{sol}}\right)$ en totale reaksie-energie $\left(\Delta \mathrm{G}_{\mathrm{rxx}}\right)$ vir die termodinamiese siklus met behulp van DFT funksionaal M06, M062X en B3LYP

TABEL S3: Termodinamiese parameters van die reduksieproses

\begin{tabular}{|c|c|c|c|c|c|c|}
\hline & $\Delta S$ & $\Delta \mathbf{G}_{\text {gas }}$ & $\Delta \Delta \mathrm{G}_{\text {sol }}$ & $\Delta \mathrm{G}_{\mathrm{rxt}}(\mathrm{M} 06)$ & $\Delta \mathrm{G}_{\mathrm{rxt}}(\mathrm{M} 062 \mathrm{X})$ & $\Delta \mathrm{G}_{\mathrm{rxt}}(\mathrm{B} 3 \mathrm{LYP})$ \\
\hline 1 & $-6.26 \mathrm{E}-04$ & -0.280 & -1.425 & -4.363 & -4.819 & -4.064 \\
\hline 2 & $-5.71 E-04$ & -0.247 & -1.673 & -4.438 & -4.899 & -4.131 \\
\hline $3 f$ & $-5.99 E-04$ & -0.252 & -1.528 & -4.506 & -4.990 & -4.190 \\
\hline $3 m$ & $-5.71 \mathrm{E}-04$ & -0.254 & -1.529 & -4.502 & -4.983 & -4.181 \\
\hline 4 & $-6.53 E-04$ & -0.274 & -1.435 & -4.609 & -5.100 & -4.262 \\
\hline $5 f$ & $-5.17 E-04$ & -0.217 & -1.296 & -5.028 & -5.521 & -4.778 \\
\hline $5 m$ & $-5.44 \mathrm{E}-04$ & -0.225 & -1.297 & -5.022 & -5.531 & -4.772 \\
\hline $6 f$ & $-5.99 E-04$ & -0.242 & -1.273 & -5.084 & -5.607 & -4.803 \\
\hline $6 m$ & $-6.53 E-04$ & -0.260 & -1.286 & -5.084 & -5.596 & -4.817 \\
\hline $7 f$ & $-5.99 E-04$ & -0.250 & -1.316 & -5.106 & -5.630 & -4.820 \\
\hline $8 f$ & $-5.71 \mathrm{E}-04$ & -0.233 & -1.253 & -5.100 & -5.608 & -4.805 \\
\hline $8 m$ & $-5.71 \mathrm{E}-04$ & -0.241 & -1.257 & -5.079 & -5.583 & -4.796 \\
\hline 9 & $-5.71 \mathrm{E}-04$ & -0.226 & -0.988 & -5.775 & -6.288 & -5.567 \\
\hline $10 f$ & $-5.99 E-04$ & -0.249 & -1.272 & -4.885 & -5.386 & -4.616 \\
\hline $10 \mathrm{~m}$ & $-5.44 \mathrm{E}-04$ & -0.229 & -1.270 & -4.898 & -5.404 & -4.612 \\
\hline
\end{tabular}

